\title{
Patterns of skeletal integration in birds reveal that adaptation of element shapes enables coordinated evolution between anatomical modules. (supplement)
}

\author{
Andrew Orkney ${ }^{(a, 1, b, *)}$, Alex Bjarnason ${ }^{(a, 1, c)}$, Brigit C. Tronrud ${ }^{(a, d)}$ \\ and Roger B.J. Benson $(a, e)$
}

June 14, 2021

a Department of Earth Sciences, University of Oxford, 3 S Parks Rd, Oxford, OX1 $3 \mathrm{AN}$,

1 Joint first authors

b https://orcid.org/0000-0003-4972-2541

c https://orcid.org/0000-0002-5127-0196

d https://orcid.org/0000-0003-2019-7157

e https://orcid.org/0000-0001-8244-6177

* Corresponding author: 01256763335

andrew.orkney@earth.ox.ac.uk

\section{Methods- Foot Use Ecology Characters}

1: Walking Ability Absent, taxon has been clearly documented as having inability to walk (0); Present, Taxon either can walk or has not been clearly documented as havng inability to walk (1).

A bird that can stride, hop or otherwise step while holding their body off of the ground can be here categorised as having ground walking ability. Scoring a taxon as character state 1 requires the explicit documentation, written or visual, of walking ability as defined previously. This character is paired with character 2 , which elaborates on the lifestyle of birds.

The majority of extant birds have the ability to walk on the ground, yet many arboreal birds rarely do so, and it is difficult to obtain specific information about whether they are capable of groundwalking or not. An example of such taxa from this dataset is the common sunbird-asity (Neodrepanis coruscans). This taxon was treated as having insufficient documentation of walking inability (character 1 , state 1). Notable, all taxa in this dataset which had such scoring difficulties due to lack of documentation lead predominantly arboreal lifestyles (character 2 state 0 ).

In addition, some aquatic birds that either spend the majority of their time in the water or in the air have become so specialised to those locomotory modes that their ability to walk is substantially hindered. Loons (Gaviidae) are able to push themselves along the ground when necessary with their body in contact with the ground, but are incapable of holding their bodies off of the ground [1], and so would be scored for character 1 as state 0. The Ascension Frigatebird (Fregata aquila) comes 
ashore only for breeding, and is only able to perch while on land [2], and is likewise scored as state 0 for character 1 . Some other well-documented examples of birds that cannot walk include swifts (Apodidae), many hummingbirds (Trochilidae), and trogons (Trogonidae).

2: Terrestrial vs Aboreal Taxon is predominantly terrestrial (or aquatic) (0); 'Mixed' state: taxon has approximately equal preference for terrestrial and arboreal spaces (1); Taxon is predominantly arboreal (2). This character scores taxa on their preferred substrate when on land, either on the ground or water (state 0 ), or above ground (state 1). In this dataset, a taxon may be scored as both arboreal (state 1) and able to walk on the ground (character 1, state 1), such as the Eurasian Sparrowhawk (Accipiter nisus), or they may be scored as both arboreal (state 1) and unable to walk (character 1, state 0), such as the Short-tailed Swift (Chaetura brachyura) and the Ascension Frigatebird (Fregata aquila). Likewise, a taxon may be scored as both terrestrial (state 0) and able to walk on the ground (character 1, state 1), such as the New Zealand Rockwren (Xenicus gilviventris). Through the inclusion of primarily aquatic birds, a taxon in this dataset may be scored as terrestrial (state 0 ) and unable to walk (character 1, state 0), such as the Red-throated Loon (Gavia stellata) and the White-tailed Tropicbird (Phaethon lepturus); these taxa are scored as terrestrial because of their terrestrial nesting substrate (character 3, state 0). Additionally, some taxa in this dataset have been scored as having 'mixed' stratification, in that they spend a non-preferential amount of time in both terrestrial and arboreal spaces. Such taxa include the Common Woodpigeon (Columba palumbus) and the American Crow (Corvus brachyrhynchos).

3: Nesting substrate Taxon nests on the ground and/or non-arboreal horizontal surface (0); 'Mixed' state: taxon has non-preferential substrate for nesting (1); Taxon nests above ground, in tree or on vertical surface (2). Regardless of the scoring of character 2, a taxon may construct or position a nesting site either on the ground or a level, terrestrial surface (state 0), or in a tree or attached to a vertical surface (state 1). Ground nesting may refer to mounds, burrows, or nests positioned on the water surface. Tree nesting may refer to nests on branches or tree cavities, in arboreal termitaria, on the walls of chimneys or other similar vertical structures, or any nest suspended above the ground surface.

In this dataset, a taxon may be scored as both ground nesting (state 0) and terrestrial (character 2, state 0), such as geese (Anser) and the Lesser Yellow-headed Vulture (Cathartes burrovianus), or both ground nesting (state 0) and arboreal (character 2, state 1), such as the Common Kingfisher (Alcedo atthis). Likewise, a taxon in this dataset may be scored as both tree nesting (state 1) and predominantly arboreal (character 2, state 1), such as the Green Woodhoopoe (Phoeniculus purpureus) and the Tawny Owl (Strix aluco), or may be scored as both tree nesting (state 1) and terrestrial (character 2, state 0), such as the Grey-winged Trumpeter (Psophia crepitans), and the Secretarybird (Sagittarius serpentarius). Some nest structures of note, which were ultimately scored as state 1 (above ground), were those of the Collared Crescentchest (Melanopareia torquata), which builds its nest low in a grass tussock [3], and the Thrush-like Antpitta (Myrmothera campanisona), which is similar in behaviour to the Tepui Antpitta (Myrmothera simplex) in constructing nests in the leaf-bases of philodendron plants [4]. As well, the Limpkin (Aramus guarana) is notable in its disparity of nesting substrates, including on floating vegetation, in shrubs, and high on tree branches [5] and so was scored as the only 'mixed' state for this character.

4. Cursorial No, taxon not specialised for running efficiency (0); Yes, taxon specialised for running efficiency (1) Birds categorised as cursorial are those which have adapted to running as their preferred method of locomotion, regardless of wing function or other foot use. Their tarsometatarsi 
(and lower leg bones in general) tend to be longer and thinner in proportion [6]. This elongation of both tibiotarsus and tarsometatarsus allows the femur to remain in horizontal position with distal end situated anteriorly, while the rest of the leg rotates at the knee joint for the running motion $[7,8]$. Taxa were scored on video observation of locomotion [1]. In the case of Galliformes, Gruiformes, Ciconiiformes, Procellariiformes, and Charadriiformes, which are known for their walking behaviours, cursoriality has been scored on the basis of their behaviour during flight take-off from a solid substrate. Taxa such as herons and bitterns (Ardeidae), shoebills (Balaenicipitidae), and partridge (Rollulus) do not run before taking flight, only jumping once into the air, and so are scored as non-cursorial (state 0). Conversely, killdeer (Charadriidae), godwits (Limosa), avocets (Recurvirostridae), Secretarybirds (Sagittarius), guineafowl (Numididae) and cranes (Gruidae) do break into a run when they take flight, and are scored as cursorial (state 1). If a taxon has well-documented running ability, such as seriemas (Cariamidae), which have a moment during full speed cursorial locomotion when both feet are off the ground [9], then they may be scored as cursorial (state 1) regardless of flight take-off movements. Waterfowl such as ducks, geese, and swans (Anseriformes), although occasionally running for take-off, have not adapted to and do not prefer running or walking as their primary mode of locomotion, and so are scored as state 0 . In an article concerning the allometry of the hindlimb in cursorial birds, [10] studied a small number of taxa which are known to walk and run, and which run rather than fly as a first resort when disturbed. After scoring the taxa in this dataset on the character rules stated above, the coding scheme reached following our specifications was similar to that applied by [10]. All cursorial birds in this dataset have well-documented ground walking ability (character 1, state 1; above), as well as a range of perching abilities, but none in this dataset are scored as being able to digitally manipulate objects (character 10), having webbed feet (character 17) or are scored as scansorial (character 14) in nature. Apart from the kiwi (Apteryx), none are scored as swimming (character 16). All taxa scored as cursorial have anisodactylous digit arrangements (character 7, state 1). As explained above, examples of cursorial birds from this dataset include the Southern Brown Kiwi (Apteryx australis) and the Secretarybird (Sagittarius serpentarius). Examples of non-cursoriality in this dataset include taxa such as the Red-fan Parrot (Deroptyus accipitrinus) and the Black-spotted Barbet (Capito niger). It is also possible for a bird to be habitually groundwalking and lack cursoriality, such as the Little Bittern (Ixobrychus minutus).

5. Hopping No, taxon does not hop as primary form of ground locomotion (0); 'Mixed' state: taxon non-preferentially uses both hops and walking strides during ground locomotion (1); Yes, taxon hops, with either one or two feet, as primary form of ground locomotion (2) Birds categorised as having hopping ability are those which can hop on either one or both feet and become momentarily airborne, as their primary mode of locomotion along a ground surface without the use of wings for lift. This character is unrelated to general ground walking ability. Both in-phase and out-of-phase hopping are counted as overall hopping ability [11]. Birds with hopping ability from this dataset include the Collared Crescent chest (Melanopareia torquata) and the Black-spotted Barbet (Capito niger). This dataset also includes 'mixed' state birds, which make equal use of both walking and hopping locomotion on the ground, such as corvids (Corvidae). Birds in this dataset scored as state 0 either make primary use of walking or running gaits for ground locomotion, such as the Hamerkop (Scopus umbretta), or lead primarily stationary or arboreal lifestyles, such as the Malay Hawk-cuckoo (Hierococcyx fugax).

6. General Perching No, taxon cannot perch (0); Yes, taxon can perch (1) Birds here characterized as having perching ability are able to hold onto a branch or structure at any height above ground, provided that their toes are curving and grasping onto the branch rather than merely stand- 
ing and balancing. Most species within Telluraves are capable of perching; examples of birds without perching abilities include swifts (Apodidae), Aequorlitornithes [12], Galloanserae, and Paleognathae. The primary element of the foot that allows birds to perch is the opposable, or 'reversed' hallux (digit 1) $[13,14]$, and its overall strength as a digit.

Digit Arrangement Characters Bird species vary in the orientations of their pedal digits, and these arrangements assist in the performance of foot-related behaviours, such as locomotion, perching, and manipulation of objects $[13,15,16]$. Some taxa, such as owls (Strigiformes) and mousebirds (Coliiformes), show behavioural variability, in which certain digit arrangements may be employed facultatively, in addition to one or many other arrangements. For example, owls are described as having 'semi-zygodactyl' [13] arrangements, which describes the alternating use of both anisodactyly and zygodactyly under normal circumstances, to fit the functional requirements of specific actions $[13,15]$. From this, the position of digits may influence the morphology of the tarsometatarsus, especially if digit arrangement has significant implications for function across multiple independently evolved groups. Each arrangement (anisodactyl, zygodactyl, heterodactyl) has been separated into its own binary character. Facultative arrangements such as semi-zygodactyly are scored as state 1 (present) for both anisodactyly (character 7) and zygodactyly (character 8).

7. Anisodactyly No, taxon has another digit arrangement (0); Yes, taxon has anisodactyl digit arrangement (1) Birds that are able to arrange their toes such that digit 1 (hallux) is directed posteriorly, and digits 2, 3, and 4 are directed anteriorly. Most extant bird taxa have this digit arrangement.

8. Zygodactyly No, taxon has another digit arrangement (0); Yes, taxon has zygodactyl digit arrangement (1) Birds that are able to arrange their toes such that digits 1 (hallux) and 4 are directed posteriorly, and digits 2 and 3 are directed anteriorly. Examples of taxa from this dataset with zygodactyl arrangements include parrots (Psittaciformes), cuckoos (Cuculiformes), and woodpeckers, jacamars, and allies (Piciformes) [17]. Taxa with facultatively zygodactyl arrangements include owls (Strigiformes), mousebirds (Coliiformes), turacos (Musophagiformes) [17], and kites (Elanus) [18].

9. Heterodactyly No, taxon has another digit arrangement (0); Yes, taxon has heterodactyl digit arrangement (1) Birds that are able to arrange their toes such that digits 1 (hallux) and 2 are directed posteriorly, and digits 3 and 4 are directed anteriorly. The heterodactyl arrangement is unique to trogons (Trogonidae) among extant birds $[13,19]$.

10. Digital manipulation No, taxon does not digitally manipulate prey and/or objects (0); Yes, taxon does manipulate prey and/or objects (1) Birds with digital manipulation ability are here defined as using their feet and toes to manipulate objects such as food items. Most extant bird species, including many falconiforms and accipitriforms, do not use their feet for digital manipulation, however examples of those that do (state 1) from this dataset are parrots (Psittaciformes), owls (Aegolius, Tyto) and the falconiform Crested Caracara (Caracara cheriway) [16].

11. Ability to hold down objects No, taxon does not hold down objects (0); Yes, taxon does hold down objects (1) This variable refers to birds that hold or pin down prey or other objects with force and bodyweight while picking at it with the beak. The action is a prolonged, forceful step onto the prey, to counteract pulling force from the beak. This action is judged independently of foot grip strength, as there are non-raptorial species which exhibit hold-down behaviour (ex. black crowned crane (Balearica pavonina)), as well as species whose grips are weak yet nevertheless exhibit 
hold-down behaviour (ex. new world vultures (Cathartidae)). The amount of force put on the feet in the hold-down position, for an important activity such as feeding, should exert some amount of influence in the shape of the foot bones in species which hold down objects [20]. Most taxa in this dataset scored with the ability to hold down objects (state 1 ) are raptorial (character 15, state 1 ) and have a force grip (character 12, state 1) as well, and all taxa are scored as able to perch (character 6, state 1). Most have ground walking ability (character 1, state 1), and few can digitally manipulate objects (character 10). There is a mix of anisodactyl and zygodactyl digit arrangements among these taxa(characters 7 and 8). None are scored as scansorial (character 14), but parrots (Psittaciformes) exhibit hanging and clinging behaviour (character 13, state 1). None are flightless (character 20) or swimming (character 16).

12. Force Grip No, taxon does not grip objects forcefully (0); Yes, taxon does grip objects forcefully (1) A 'force grip' is here defined as the use of a foot or the feet in order to grip onto an object, usually in the capture and carry of prey, exerting force and closing talons to maintain grasp. This ability is commonly associated with structures such as digital tendon locking mechanisms [21], so that the force behind such a grip can be efficiently maintained [22]. Like perching, forceful gripping is also facilitated by the reversal of the hallux [16], as well as by certain digital arrangements such as anisodactyly and zygodactyly $[15,23,24]$. All taxa in this dataset scored as having a force grip (state 1) also have the ability to perch (character 6 , state 1), and to hold down objects (character 11, state 1). Most taxa with a force grip are also scored as raptorial (character 15, state 1), with the exception of parrots (Psittaciformes). Most are anisodactyl; the parrots (Psittaciformes) and owls (Strigiformes) are zygodactyl and semi-zygodactyl respectively. Only one taxon, the Secretarybird (Sagittarius serpentarius) is scored as cursorial. None are flightless (character 20) or swimming (character 16). The majority of extant bird species do not exhibit forceful gripping behaviour; examples of taxa from this dataset which do employ force grips include most members of raptorial clades (Accipitriformes, Falconiformes, Strigiformes) as well as parrots (Psittaciformes).

13. Hanging and Clinging Behaviour No, taxon does not use the feet to hang or cling on branches or vertical surfaces (0); Yes, taxon does use the feet to hang or cling on branches or vertical surfaces (1) [25] determined that hanging locomotion results in varied moment arms and relative tarsometatarsus lengths among parrots (Psittacidae), tits (Parus), and goldcrests (Regulus). However, in combination with feeding movements, these taxa may rely more on stability of the tarsometatarsus [25], in the form of shorter overall bone length [26]. Taxa with hanging and clinging behaviour are mixed in other shared ecological categories in this dataset: none are here scored as cursorial (character 4), raptorial (character 15), flightless (character 20), or swimming (character 16); only some exhibit scansoriality (character 14) in addition to hanging and clinging behaviour; all but swifts (Apodidae) are able to perch (character 6) as well as hang and cling; all share a mix of anisodactyl and zygodactyl digit arrangements (characters 7 and 8), apart from the swifts (Apodidae) and mousebirds (Coliiformes), which are capable of pamprodactylous (character 10, state 1) toe configurations in addition to anisodactyly. Extant birds from this dataset that hang from branches include parrots (Psittaciformes) and mousebirds (Coliidae); birds that cling to vertical surfaces include swifts (Apodidae).

14. Scansorial No, taxon does not climb vertical surfaces (0); Yes, taxon does climb vertical surfaces (1) Scansorial birds climb vertical surfaces by hopping or walking upwards. The use of this term signifies only the presence of vertical climbing behaviour, not necessarily a primary or frequent preference for this style of locomotion, as the term has been used in other research. Zeffer and Nor- 
berg (2003) [25] determined that climbing locomotion correlates with higher than average distances between the eminentia intercotylaris and the m. tibialis cranialis insertion point, resulting in a focus on force production during ankle flexion, rather than speed. In this dataset, only four taxa are scored as scansorial. All four share a number of other ecological scores. All can hang and cling (character 12, state 1 ), perch (character 6 , state 1 ), and have standard walking ability (character 1 , state 1 ). There is a mix of anisodactyl and zygodactyl digit arrangements (characters 7 and 8) in this category; the Black-tailed Treecreeper (Climacteris melanurus) and the Common Hoopoe (Upupa epops) are anisodactylous (character 7, state 1), and the Least Honeyguide (Indicator exilis) and the Eurasian Wryneck (Jynx torquilla) are zygodactylous (character 8, state 1). None of the taxa scored here as scansorial are also scored as cursorial (character 4), raptorial (character 15), flightless (character 20) or swimming (character 19).

15. Raptorial Behaviour No, taxon does not strike and carry prey with the feet (0); Yes, taxon does strike and carry prey with the feet (1) Despite many colloquially produced lists of birds of prey, very few researchers have explicitly defined the terms "raptor" or "bird of prey" as behavioural categories. Zeffer and Norberg (2003) [25] defined a subsection of birds of prey as those species which "carry their prey close to the body with the claws during flight," (p. 1086) to avoid drag and parasitism from other birds. Zeffer et al. (2003) [25] described their bird of prey category as those birds which "strike and carry prey with the feet," (p. 462), but excluded certain taxa (such as new and old world vultures, and Secretarybirds) to a terrestrial category instead. Ward et al. (2002) [27] referred to the term 'raptor' in connection to predatory efficiency, and the dependency on the use of hindlimbs to catch prey. Many works refer to specific taxonomic orders to define raptoriality: the Accipitriformes, Falconiformes, and Strigiformes. The definition of raptorial behaviour will here follow the [25] description of striking and carrying prey with the feet. However, unlike the classification of Zeffer et al. (2003) [25], Secretarybirds (Sagittarius serpentarius) are included in this category, as they are observed to strike and carry prey with the feet; they are also scored independently as terrestrial and cursorial, which is permitted by the multivariate classification scheme used here. Despite their vernacular status as 'raptors', vultures do not use their feet for the hunting and killing of prey unlike other Accipitriformes, and so are scored in this category with state 0 . They do not have the appropriate foot grip strength to perform this behaviour [28]. Most vultures primarily scavenge for carrion prey; although a carrion diet would not preclude their inclusion in the raptorial category outright, and although some vultures hunt and kill live prey with varying degrees of frequency, it is both unclear and unlikely that any vulture taxon uses its feet for striking in the same way that more powerful raptors do. Raptorial birds in this dataset share the ability to hold down objects (character 11 , state 1), usually combined with the use of a force grip (character 12, state 1). All taxa are either anisodactyl or semizygodactyl (a combination of anisodactyl and zygodactyl digit arrangements), with a varied mix of cursoriality (character 5) and ground walking ability (character 1). None are scansorial (character 14) or flightless (character 20). Ospreys (Pandionidae) are the only taxon scored intermediately for swimming ability as they are briefly and partially submerged after a plunging dive to catch fish.

16. Swimming Ability No, taxon cannot swim (0); Taxon exhibits plunging behaviour, i.e. briefly submerged after a dive (1); Yes, taxon exhibits a full swimming mode of locomotion (2) Birds here characterized as having full swimming ability are able to both suspend and propel themselves through water with any aquatic mode of locomotion. This includes birds which swim on the surface of water as well as those which swim with their bodies submerged. The mechanism of propulsion through the water is inclusive of wing-based locomotion as well as foot-based. The scoring of this category is 
designed to be as inclusive as possible, in order to set a basis upon which later swimming behaviour characters are built on. The intermediate scoring of plunging behaviour includes taxa which do not otherwise have a full swimming locomotion mode, yet nonetheless interact with the water as a major aspect of their behaviour. For example, the kingfishers included in this dataset (Chloroceryle, Alcedo) plunge for fish and are briefly submerged [29], but do not continue to propel themselves either under the water or on top of it, and so have intermediate scoring. The brown pelican (Pelecanus occidentalis) exhibits a similar plunging technique, yet also rests on top of the water with foot-propelled surface swimming, and so is scored as having full swimming ability. Apart from the Southern Brown Kiwi (Apteryx australis), the Hoatzin (Opisthocomus hoazin), and the Virginia Rail (Rallus limnicola) all taxa in this dataset with full swimming mode have webbed feet (character 17, state 1 or 2 ) and are not scored as cursorial (character 4). All fully swimming taxa have anisodactyl digit arrangements (character 7 , state 1), and none are scored as raptorial (character 15). Some examples of taxa from this dataset that are defined as non-swimming include wading birds such as bitterns, herons, and egrets (Ardeidae), and most Passeriformes. Most shorebirds (Charadriiformes) included in this dataset have surface swimming ability (state 2), and at least some sandpipers (Actitis, Tringa) are able to dive and propel themselves using both feet and wings.

17. Webbed Feet No, taxon does not have webbed feet or feet with toe lobes (0); Taxon has feet with toe lobes (1); Yes, taxon has webbed feet (2) Webbed feet are linked with aquatic behaviour in birds. They are found in Anseriformes, Phoenicopteriformes, Phaethoniformes, Gaviiformes, Sphenisciformes, Procellariiformes, Pelecaniformes, and Suliformes. The triangular shape and surface area of webbed feet provide efficient propulsion for swimming [30]. Most taxa with swimming ability have either webbed feet or feet with toe lobes. Toe lobes, found in grebes (Podicepedidae), finfoots (Heliornithidae), coots (Fulica), and phalaropes (Phalaropus, Steganopus) are here categorized as an intermediate score between non-webbed and webbed feet, in case there is a statistically significant distinction between morphologies. All taxa with toe lobes or webbed feet have anisodactyl digit arrangements (character 7, state 1) [13], and all except for the Ascension frigatebird (Fregata aquila) swim (character 16, state 0) [2]. In this dataset, it appears that most taxa with toe lobes or webbed feet perform foot-propelled surface swimming (character 18, state 1), and a smaller subset perform submerged foot-propelled swimming (character 18). All taxa with toe lobes or webbed feet in the current dataset are able to fly (character 20, state 0), apart from the Humboldt Penguin (Spheniscus humboldti); outside the dataset, there are a number of flightless aquatic taxa with toe lobes or webbed feet, such as the Flightless Cormorant (Nannopterum harrisi) and the Titicaca Grebe (Rollandia microptera). Most taxa scored as state 1 or 2 are able to walk on the ground (character 1 ), with the exception of the Ascension Frigatebird (Fregata aquila) and the Red-throated Loon (Gavia stellata). The Southern Brown Kiwi (Apteryx australis) and Virginia Rail (Rallus limnicola) are examples of taxa within this dataset which are able to swim but do not have webbed feet, whereas the Frigatebird (Fregata aquila) does not swim [2] but does have webbed feet. Taxa within this dataset which have feet with toe lobes include the African Finfoot (Podica senegalensis), and the White-tufted Grebe (Rollandia rolland). The Magpie Goose (Anseranas semipalmata), which has 'semipalmated' feet [31], has here been scored as state 2 , due to the presence of webbing, regardless of relative amount.

18. Foot-propelled Surface Swimming No, taxon does not propel itself along water surface using feet (0); Yes, taxon does propel itself along water surface using feet (1) Foot-propelled surface swimming describes the locomotion of a bird which sits on top of the water surface, and uses its legs and feet underneath to propel itself forward. All surface swimmers, with the exception of the Southern Brown Kiwi (Apteryx australis), the Hoatzin (Opisthocomus hoazin), and the Virginia 
Rail (Rallus limnicola) have toe lobes or webbed feet (character 17, state 1 or 2), have anisodactyl digit arrangements (character 7, state 1), and are able to fly (character 20, state 0). Examples of birds which use surface foot-propulsion include the pelican (Pelecanus), and ducks, geese, and swans (Anatidae). An example of a bird from this dataset which does not employ this method of locomotion is the Amazon Kingfisher (Chloroceryle amazona).

19. Foot-propelled Submerged Swimming No, taxon does not propel itself through water using feet while fully submerged (0); Yes, taxon does propel itself through water using feet while fully submerged (1) State 1 of this character describes the locomotion of a bird which submerges its body fully under the surface of the water, and then propels itself with the use of legs and feet. The taxa in this dataset which do engage in submerged foot propelled swimming have also been scored as having webbed feet or toe lobes (character 17, state 1 or 2) [32], anisodactyl digit arrangements (character 7 , state 1), ability to fly (character 20, state 0 ), and ability to swim on the water surface with footpropulsion (character 18, state 1). Examples of birds in this dataset which employ this method of locomotion include grebes (Podicipedidae) and ducks (Anatidae). Birds such as penguins (Spheniscidae) and gulls (Larus) are capable of swimming, but penguins do not propel with the hindlimbs, and gulls do not swim while submerged. Plunge-divers such as pelicans [33] and aquatic kingfishers become either partially or fully submerged during their dive, but do not exhibit forms of forward or upward propulsion while submerged. The Short-tailed Shearwater (Ardenna tenuirostris) and the Masked Booby (Sula dactylactra) use a combination of foot and wing propulsion during submerged swimming to lengthen their plunge dives, and are here scored as state 1.

20. Flightlessness No, bird is able to fly in any capacity (0); Yes, bird is unable to fly (1) Birds defined here as flightless are physically incapable of aerial flight, regardless of preference or facultative ability. Flightless birds tend to have more robust hindlimbs, as they must rely on and invest in their legs for locomotion [34]. Birds which are considered flightless included in this dataset include the penguin (Spheniscus) and the kiwi (Apteryx). Both taxa are able to walk (character 1, state 1) and swim (character 16, state 2), to varying extents of proficiency in each, although swimming ability for other flightless ratites is likely not common. 


\section{Supplementary Figures}

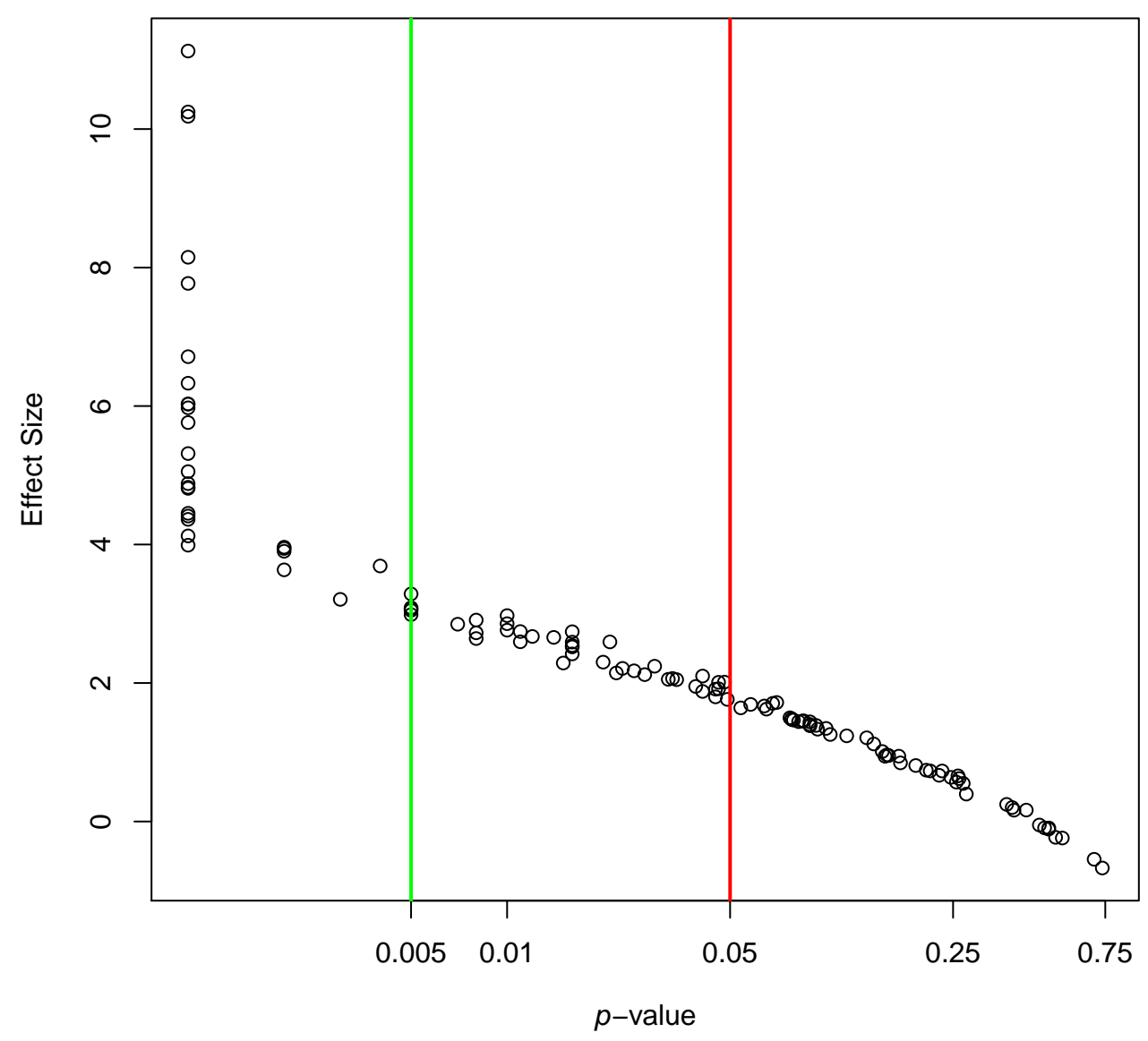

Supplementary Figure 1: Effect size of pair-wise p2BPLS analyses of element shape combinations and element shape-ecology combinations, plotted against corresponding P-values. The red line marks the threshold of $p=0.05$, while the green line marks the threshold of $p=0.005$. 

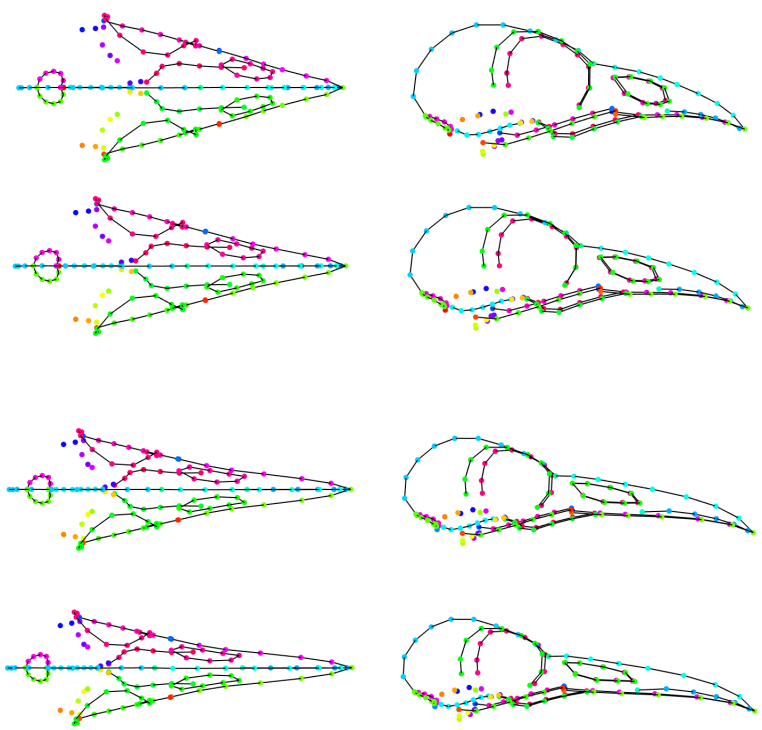

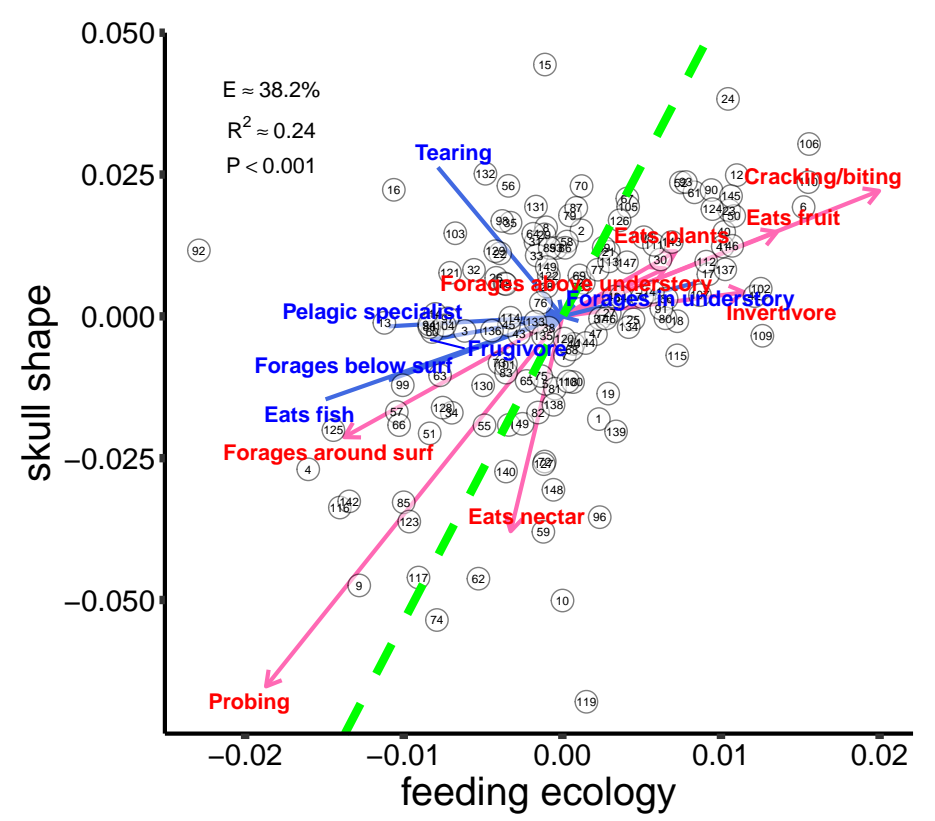

Supplementary Figure 2: Relationships for the first salience between feeding ecology and skull morphology represented by the first salience of p2BPLS analyses comparing shape to ecological trait blocks. Shape variation (y-axis) is illustrated using deviations from the mean shape derived from Procrustes superposition for the skull in dorsal and lateral views. Arrows indicate selected ecological variables that change significantly across the sum of these axes ( $p$-value $<0.05)$. Red: Ecology increases in frequency away from the grand mean. Blue: Ecology increases in frequency towards the grand mean. Birds are represented by enumerated points (see Supplementary Table 1 for the species names) E represents the portion of explained variance along this salience. 

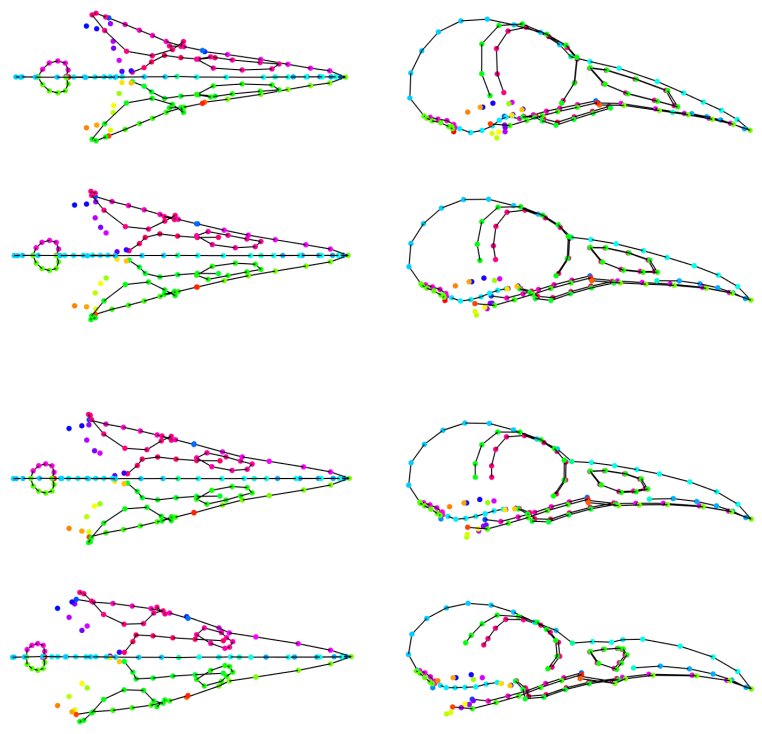
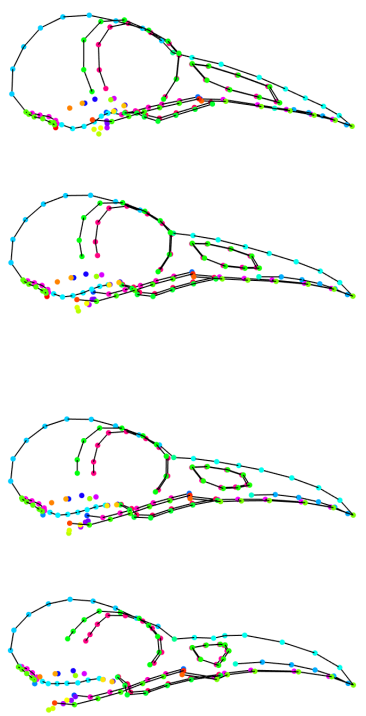

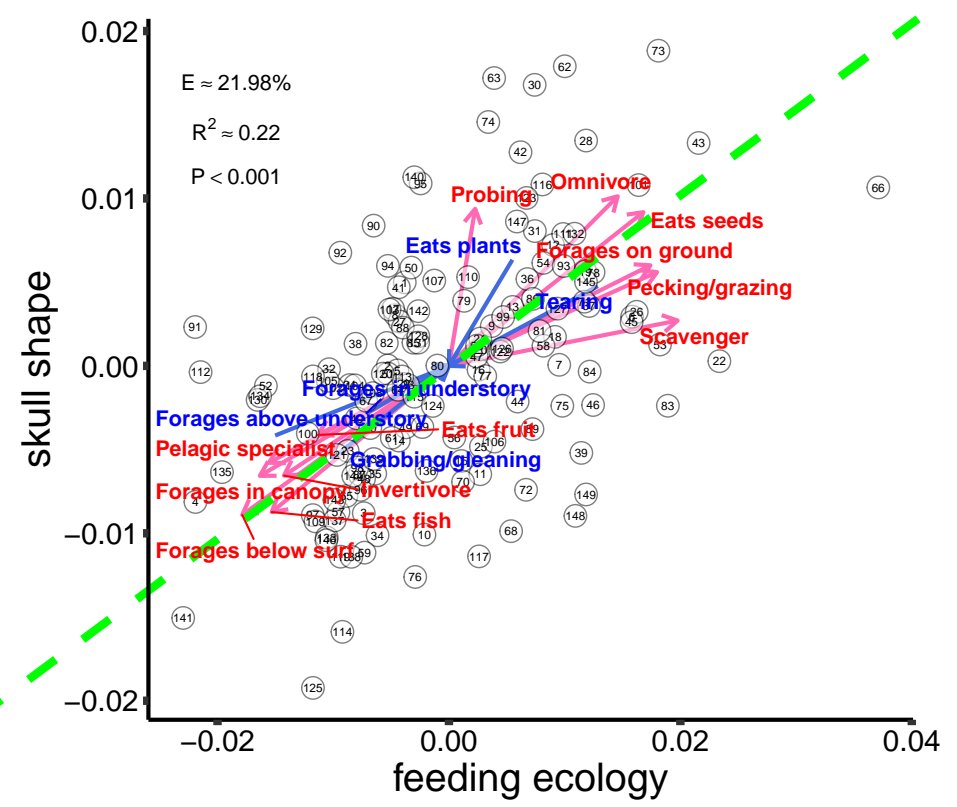

Supplementary Figure 3: Relationships for the second salience between feeding ecology and skull morphology represented by p2BPLS analyses comparing shape to ecological trait blocks. Shape variation (y-axis) is illustrated using deviations from the mean shape derived from Procrustes superposition for the skull in dorsal and lateral views. Arrows indicate selected ecological variables that change significantly across the sum of these axes $(p$-value $<0.05)$. Red: Ecology increases in frequency away from the grand mean. Blue: Ecology increases in frequency towards the grand mean. Birds are represented by enumerated points (see Supplementary Table 1 for the species names) E represents the portion of explained variance along this salience. 

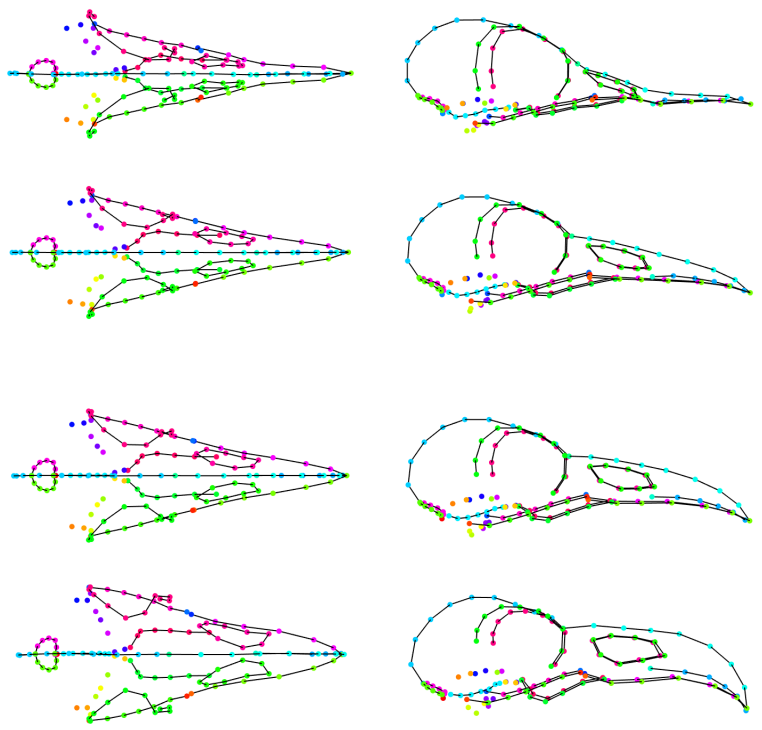

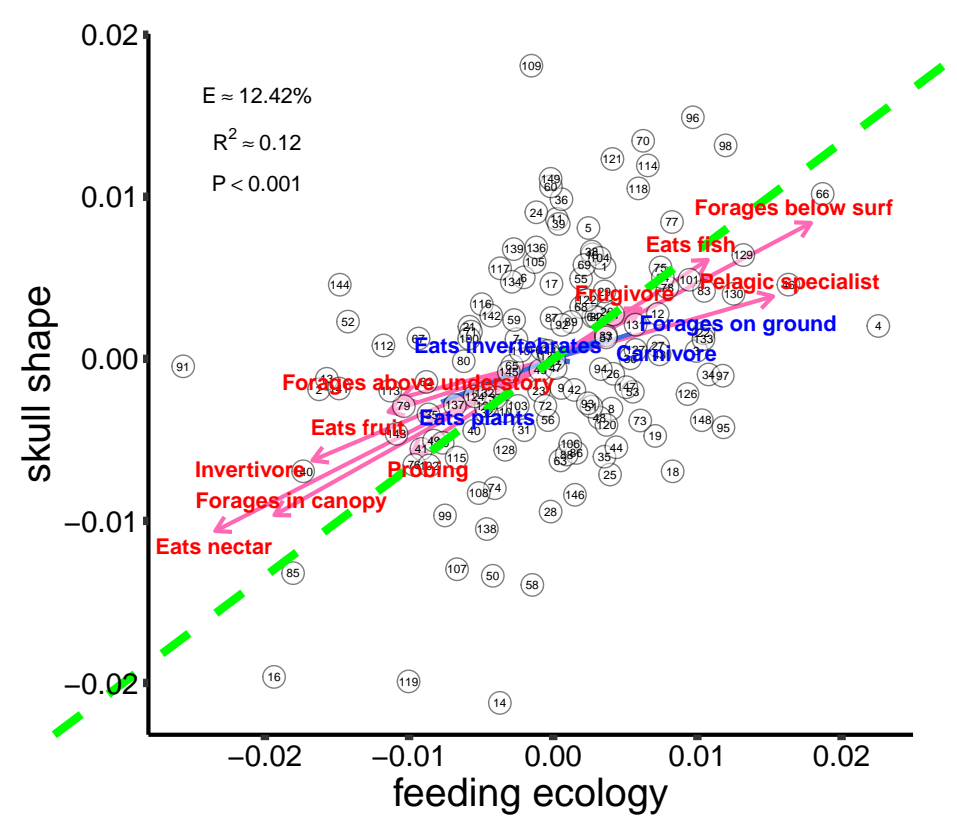

Supplementary Figure 4: Relationships for the third salience between feeding ecology and skull morphology represented p2BPLS analyses comparing shape to ecological trait blocks. Shape variation (y-axis) is illustrated using deviations from the mean shape derived from Procrustes superposition for the skull in dorsal and lateral views. Arrows indicate selected ecological variables that change significantly across the sum of these axes $(p$-value $<0.05)$. Red: Ecology increases in frequency away from the grand mean. Blue: Ecology increases in frequency towards the grand mean. Birds are represented by enumerated points (see Supplementary Table 1 for the species names) E represents the portion of explained variance along this salience. 

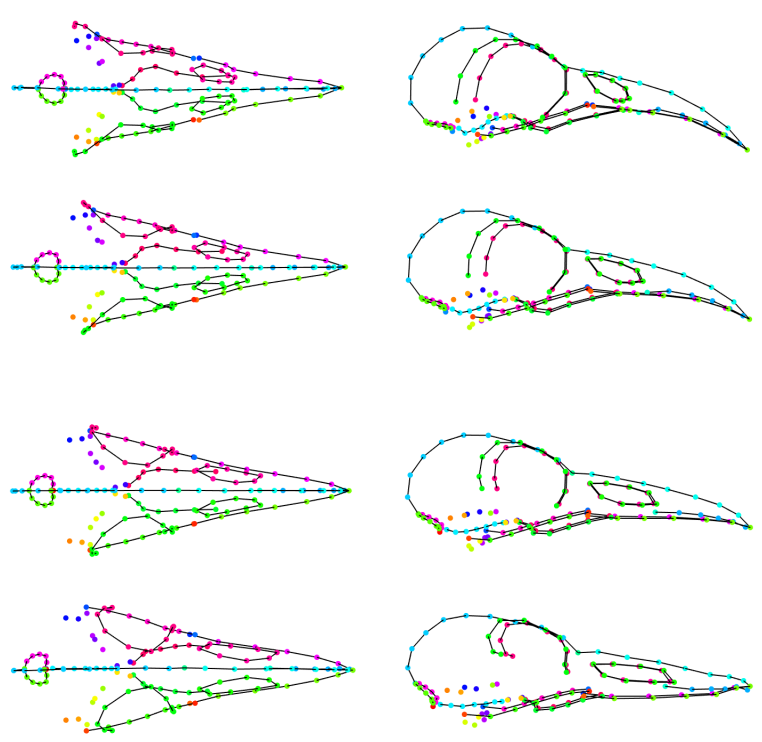

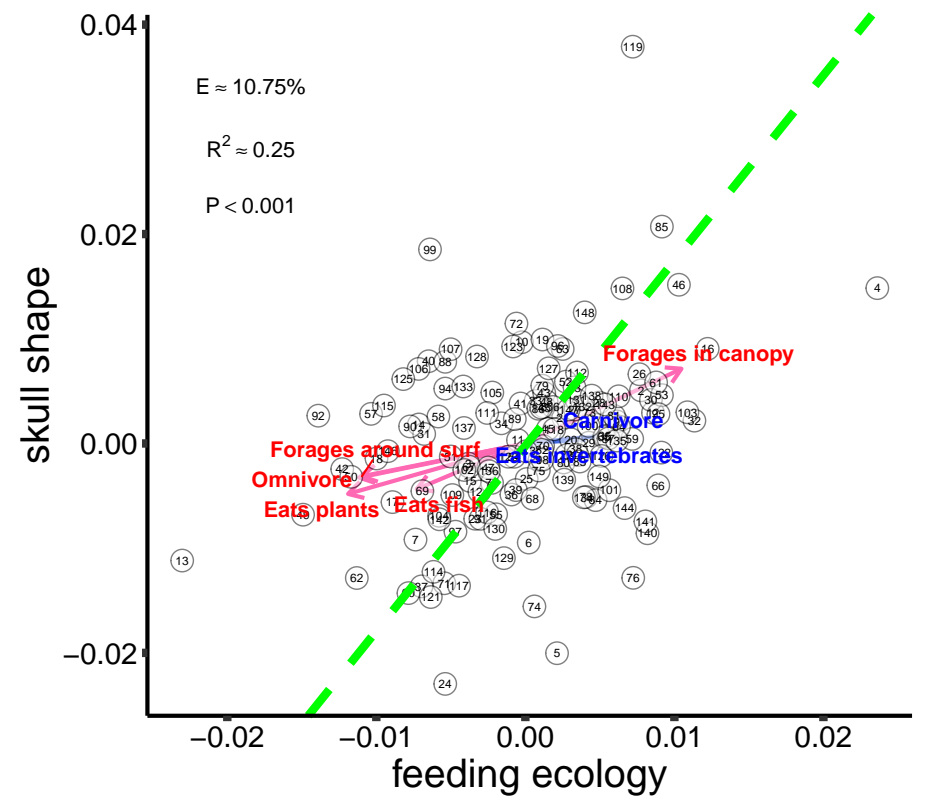

Supplementary Figure 5: Relationships for the fourth salience between feeding ecology and skull morphology represented p2BPLS analyses comparing shape to ecological trait blocks. Shape variation (y-axis) is illustrated using deviations from the mean shape derived from Procrustes superposition for the skull in dorsal and lateral views. Arrows indicate selected ecological variables that change significantly across the sum of these axes $(p$-value $<0.05)$. Red: Ecology increases in frequency away from the grand mean. Blue: Ecology increases in frequency towards the grand mean. Birds are represented by enumerated points (see Supplementary Table 1 for the species names) E represents the portion of explained variance along this salience. 


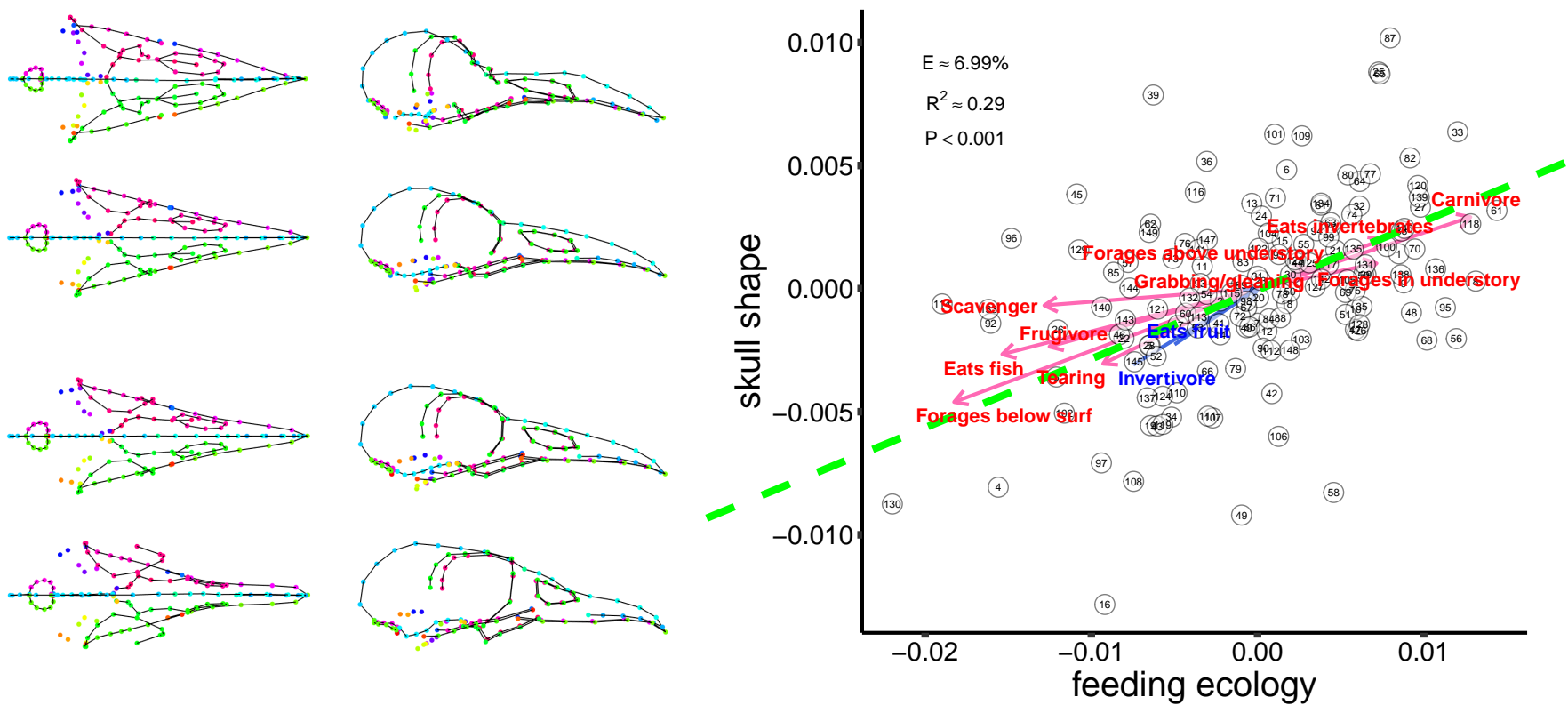

Supplementary Figure 6: Relationships for the fifth salience between feeding ecology and skull morphology represented by p2BPLS analyses comparing shape to ecological trait blocks. Shape variation (y-axis) is illustrated using deviations from the mean shape derived from Procrustes superposition for the skull in dorsal and lateral views. Arrows indicate selected ecological variables that change significantly across the sum of these axes $(p$-value $<0.05)$. Red: Ecology increases in frequency away from the grand mean. Blue: Ecology increases in frequency towards the grand mean. Birds are represented by enumerated points (see Supplementary Table 1 for the species names) E represents the portion of explained variance along this salience. 

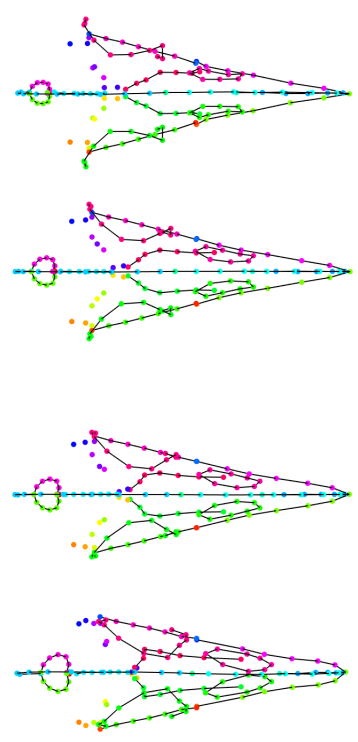
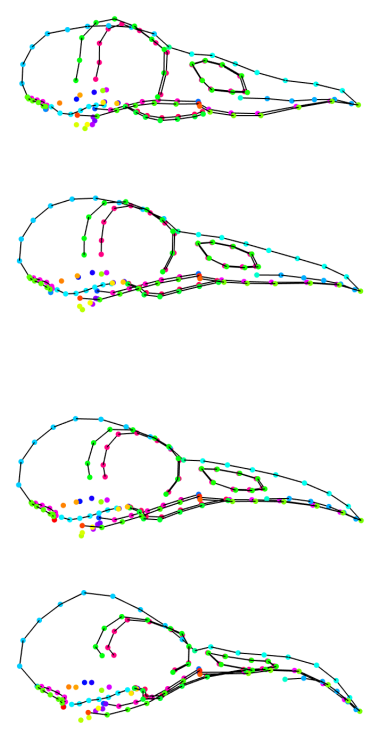

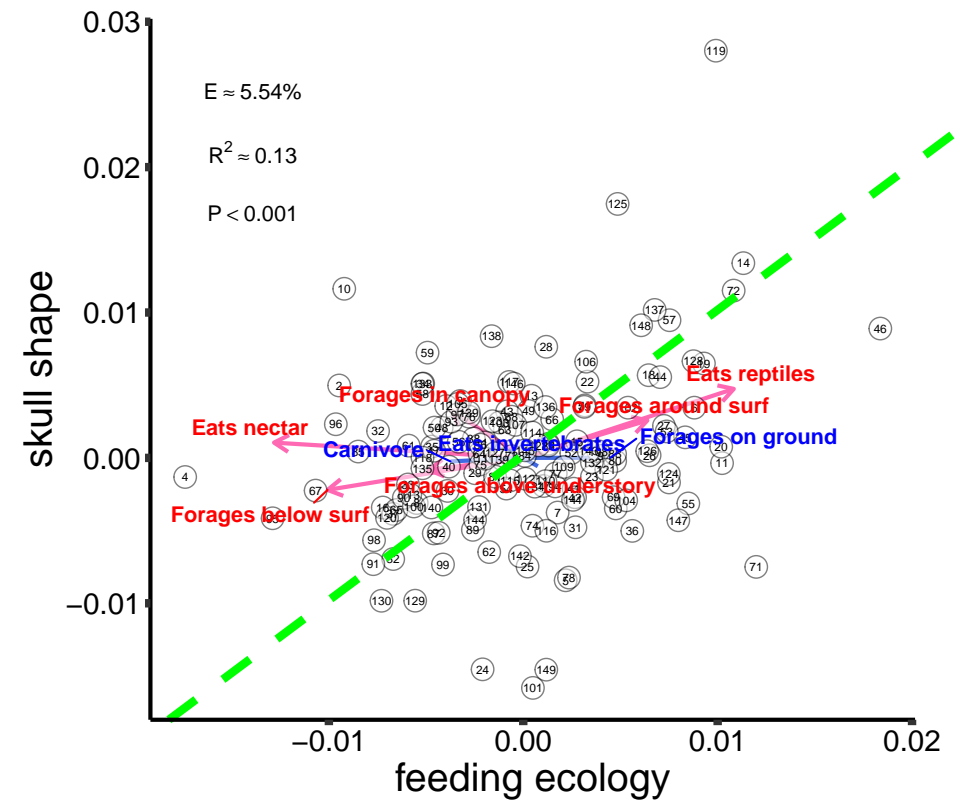

Supplementary Figure 7: Relationships for the sixth salience between feeding ecology and skull morphology represented by p2BPLS analyses comparing shape to ecological trait blocks. Shape variation (y-axis) is illustrated using deviations from the mean shape derived from Procrustes superposition for the skull in dorsal and lateral views. Arrows indicate selected ecological variables that change significantly across the sum of these axes $(p$-value $<0.05)$. Red: Ecology increases in frequency away from the grand mean. Blue: Ecology increases in frequency towards the grand mean. Birds are represented by enumerated points (see Supplementary Table 1 for the species names) E represents the portion of explained variance along this salience. 

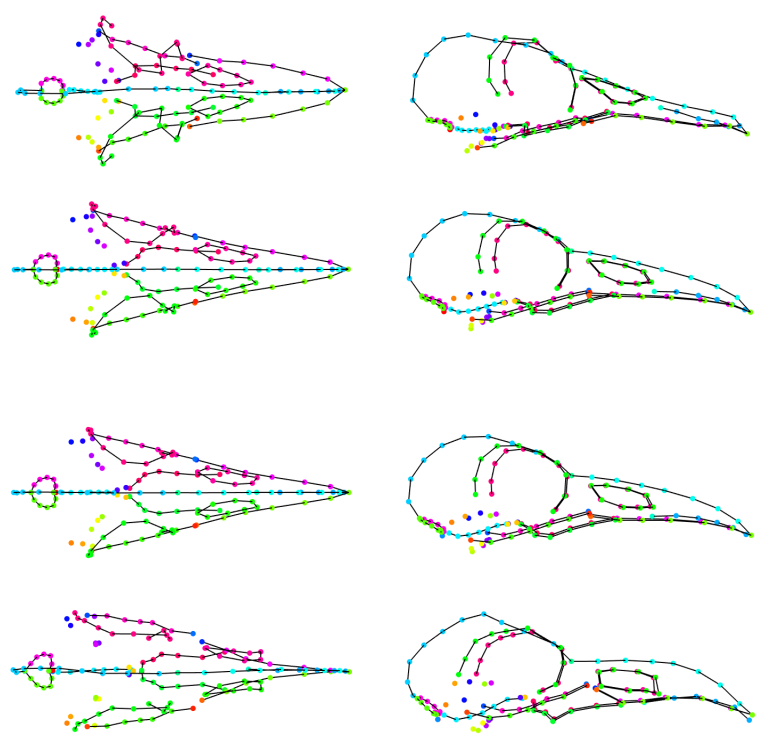

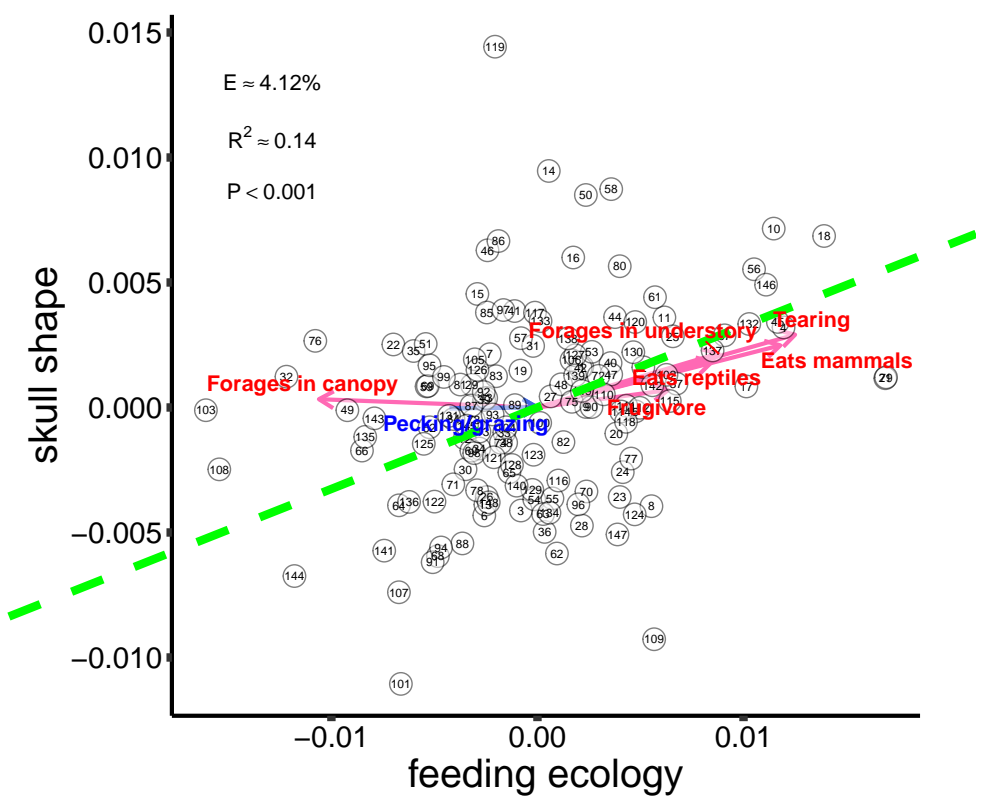

Supplementary Figure 8: Relationships for the seventh salience between feeding ecology and skull morphology represented p2BPLS analyses comparing shape to ecological trait blocks. Shape variation (y-axis) is illustrated using deviations from the mean shape derived from Procrustes superposition for the skull in dorsal and lateral views. Arrows indicate selected ecological variables that change significantly across the sum of these axes $(p$-value $<0.05)$. Red: Ecology increases in frequency away from the grand mean. Blue: Ecology increases in frequency towards the grand mean. Birds are represented by enumerated points (see Supplementary Table 1 for the species names) E represents the portion of explained variance along this salience. 

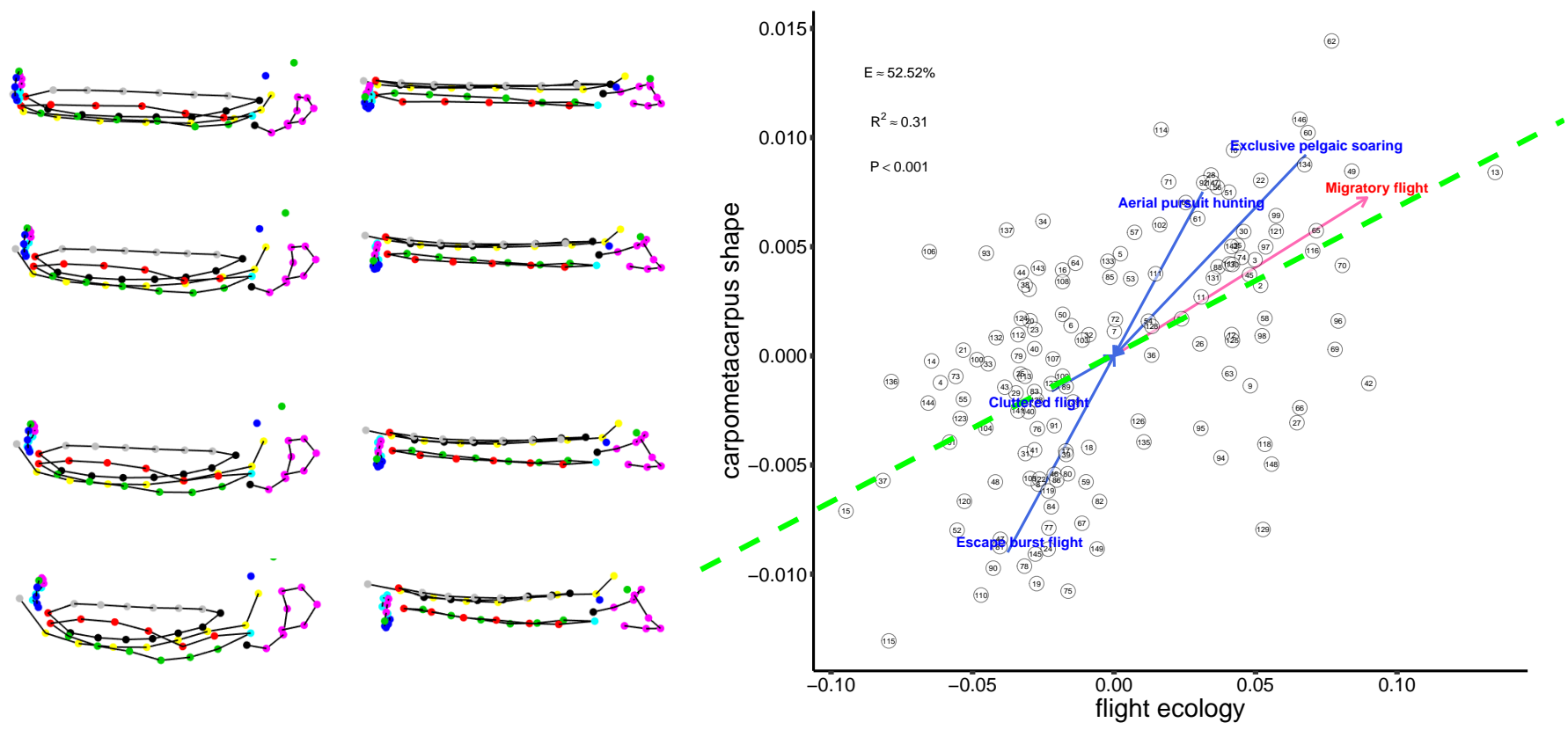

Supplementary Figure 9: Relationships for the first salience between flight ecology and carpometacarpus morphology represented by the first salience of p2BPLS analyses comparing shape to ecological trait blocks. Shape variation (y-axis) is illustrated using deviations from the mean shape derived from Procrustes superposition for the carpometacarpus in dorsal and lateral views. Arrows indicate selected ecological variables that change significantly across the sum of these axes $(p$-value $<0.05)$. Red: Ecology increases in frequency away from the grand mean. Blue: Ecology increases in frequency towards the grand mean. Birds are represented by enumerated points (see Supplementary Table 1 for the species names) E represents the portion of explained variance along this salience. 


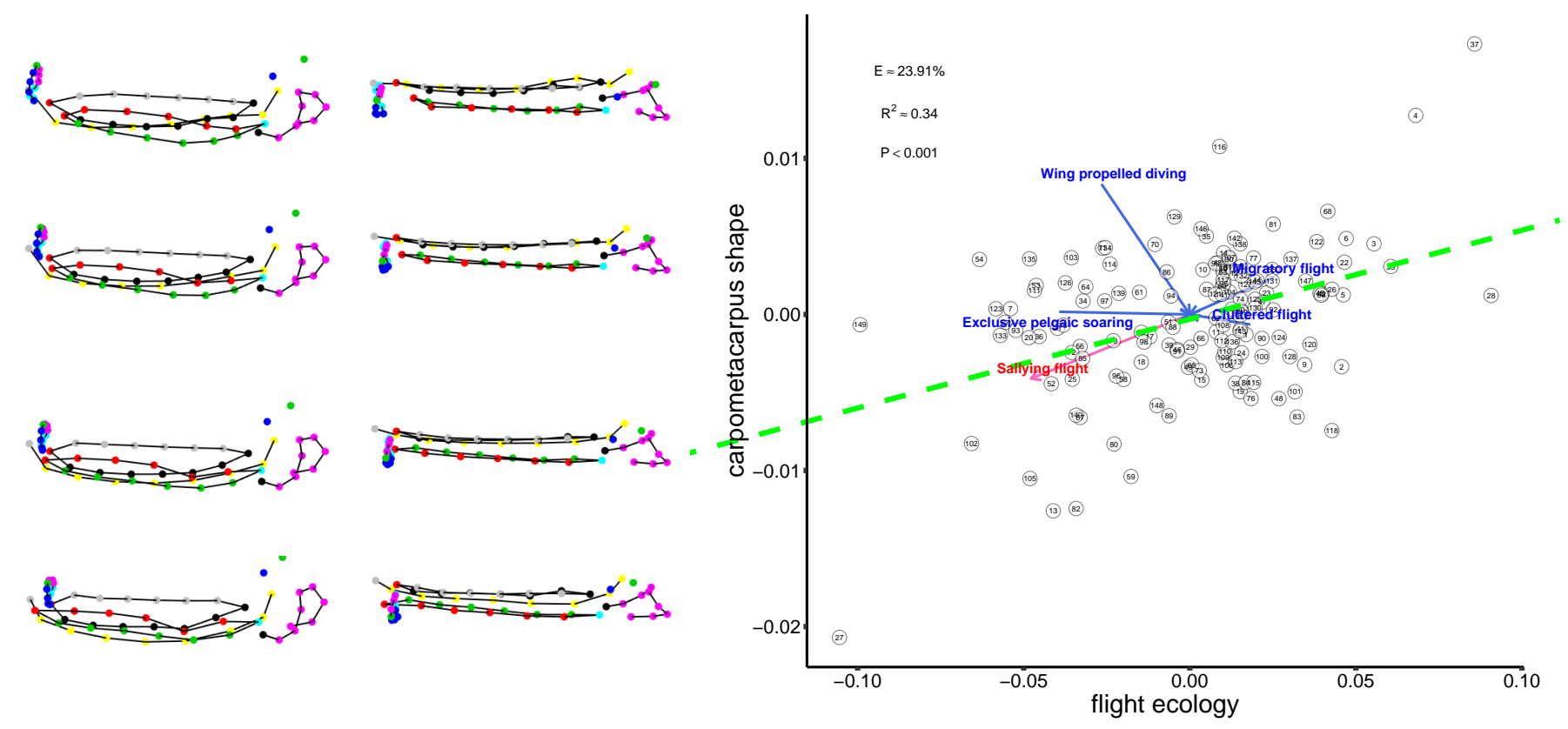

Supplementary Figure 10: Relationships for the second salience between flight ecology and carpometacarpus morphology represented by p2BPLS analyses comparing shape to ecological trait blocks. Shape variation (y-axis) is illustrated using deviations from the mean shape derived from Procrustes superposition for the carpometacarpus in dorsal and lateral views. Arrows indicate selected ecological variables that change significantly across the sum of these axes ( $p$-value $<0.05)$. Red: Ecology increases in frequency away from the grand mean. Blue: Ecology increases in frequency towards the grand mean. Birds are represented by enumerated points (see Supplementary Table 1 for the species names) E represents the portion of explained variance along this salience. 


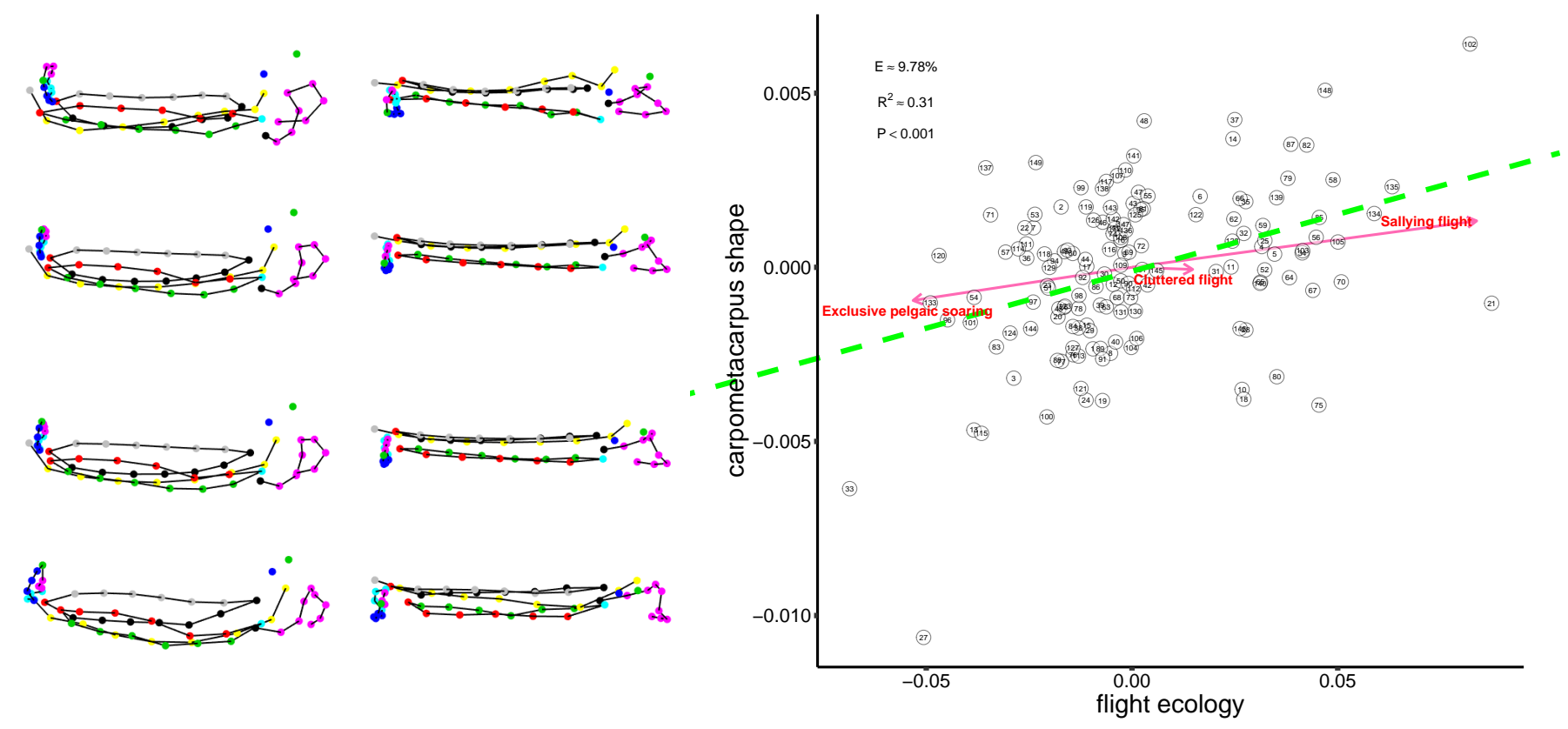

Supplementary Figure 11: Relationships for the third salience between flight ecology and carpometacarpus morphology represented by p2BPLS analyses comparing shape to ecological trait blocks. Shape variation (y-axis) is illustrated using deviations from the mean shape derived from Procrustes superposition for the carpometacarpus in dorsal and lateral views. Arrows indicate selected ecological variables that change significantly across the sum of these axes ( $p$-value $<0.05)$. Red: Ecology increases in frequency away from the grand mean. Blue: Ecology increases in frequency towards the grand mean. Birds are represented by enumerated points (see Supplementary Table 1 for the species names) E represents the portion of explained variance along this salience. 


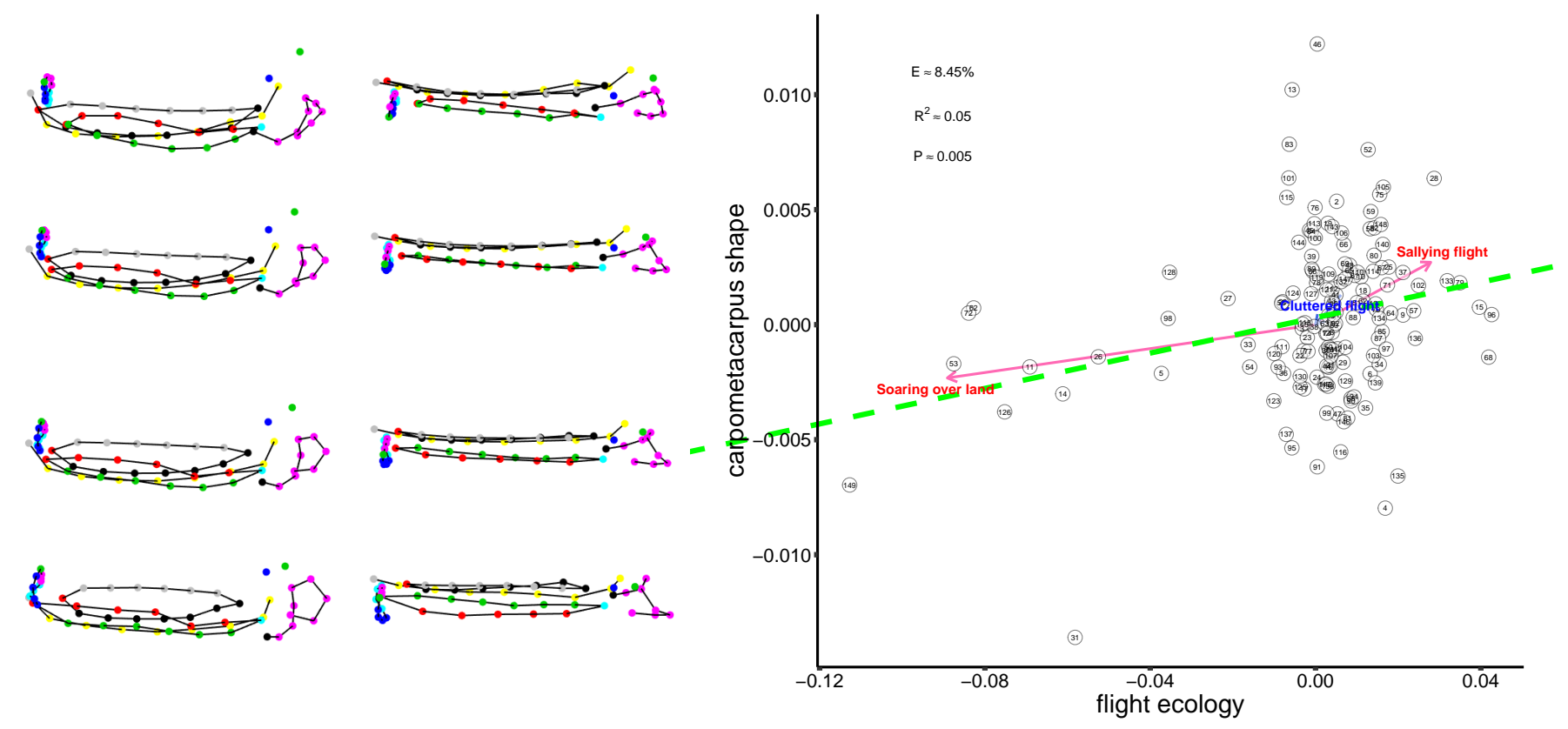

Supplementary Figure 12: Relationships for the fourth salience between flight ecology and carpometacarpus morphology represented by p2BPLS analyses comparing shape to ecological trait blocks. Shape variation (y-axis) is illustrated using deviations from the mean shape derived from Procrustes superposition for the carpometacarpus in dorsal and lateral views. Arrows indicate selected ecological variables that change significantly across the sum of these axes ( $p$-value $<0.05)$. Red: Ecology increases in frequency away from the grand mean. Blue: Ecology increases in frequency towards the grand mean. Birds are represented by enumerated points (see Supplementary Table 1 for the species names) E represents the portion of explained variance along this salience. 


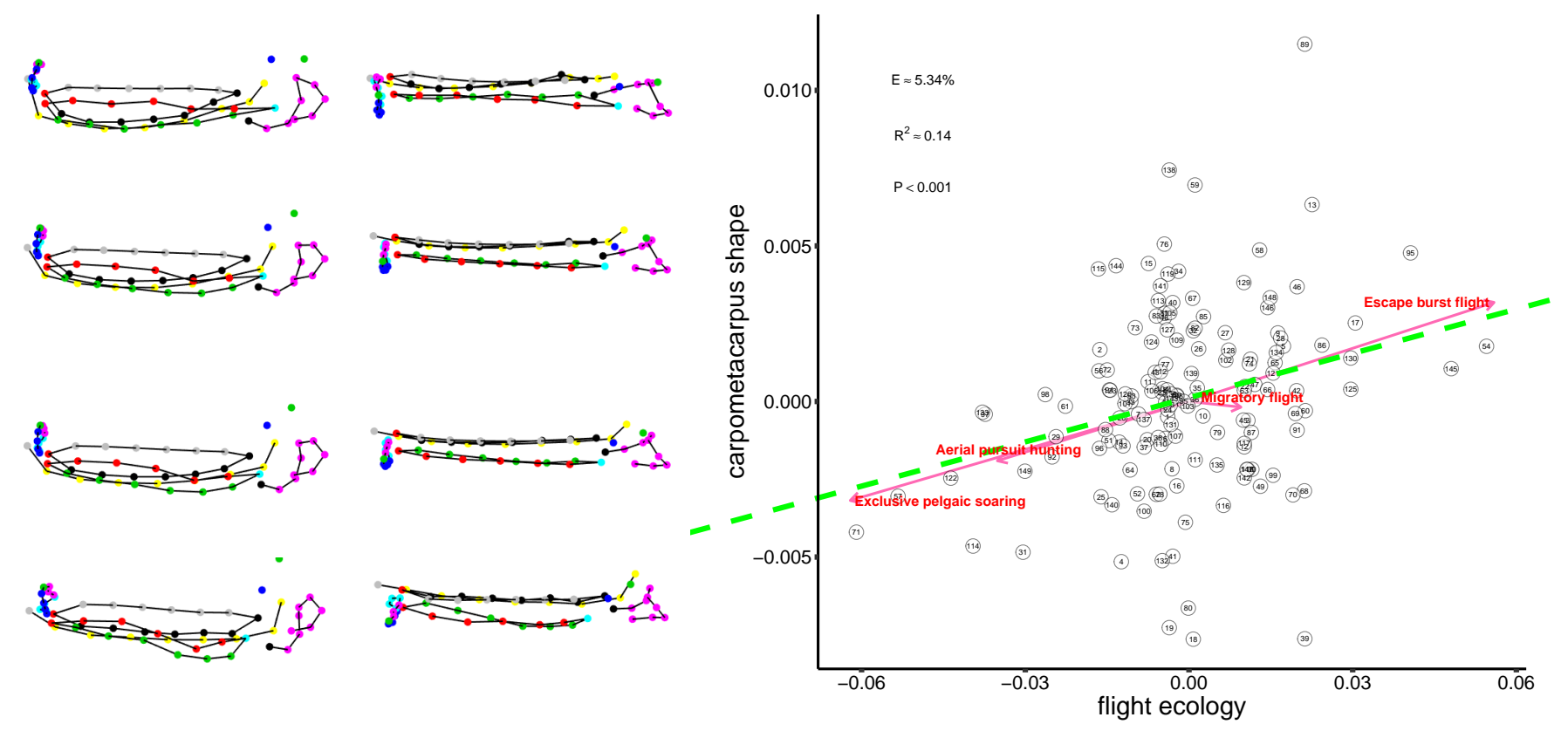

Supplementary Figure 13: Relationships for the fifth salience between flight ecology and carpometacarpus morphology represented by p2BPLS analyses comparing shape to ecological trait blocks. Shape variation (y-axis) is illustrated using deviations from the mean shape derived from Procrustes superposition for the carpometacarpus in dorsal and lateral views. Arrows indicate selected ecological variables that change significantly across the sum of these axes $(p$-value $<0.05)$. Red: Ecology increases in frequency away from the grand mean. Blue: Ecology increases in frequency towards the grand mean. Birds are represented by enumerated points (see Supplementary Table 1 for the species names) E represents the portion of explained variance along this salience. 


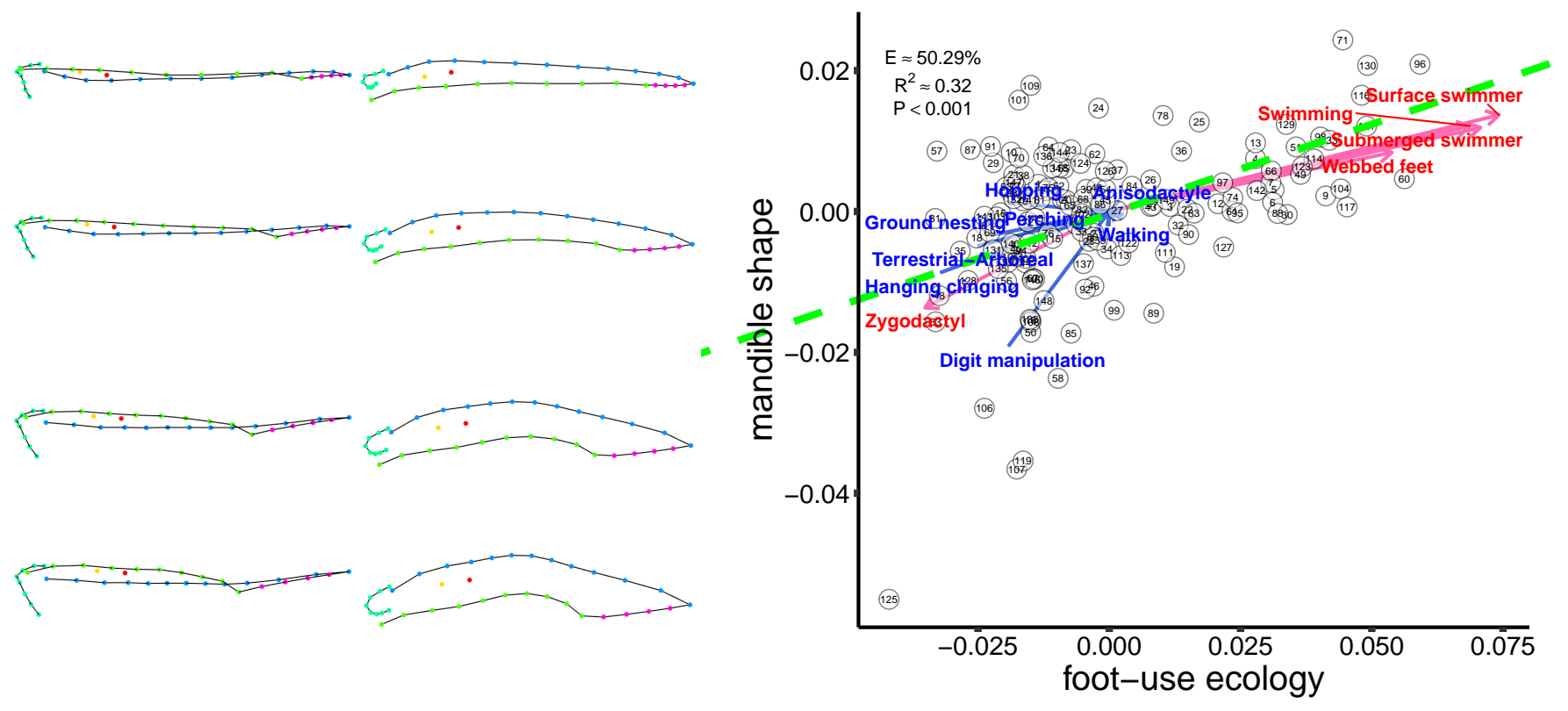

Supplementary Figure 14: Relationships for the first salience between hindlimb ecology and mandible morphology represented by the first salience of p2BPLS analyses comparing shape to ecological trait blocks. Shape variation (y-axis) is illustrated using deviations from the mean shape derived from Procrustes superposition for the mandible in dorsal and lateral views. Arrows indicate selected ecological variables that change significantly across the sum of these axes $(p$-value $<0.05)$. Red: Ecology increases in frequency away from the grand mean. Blue: Ecology increases in frequency towards the grand mean. Birds are represented by enumerated points (see Supplementary Table 1 for the species names) E represents the portion of explained variance along this salience. 


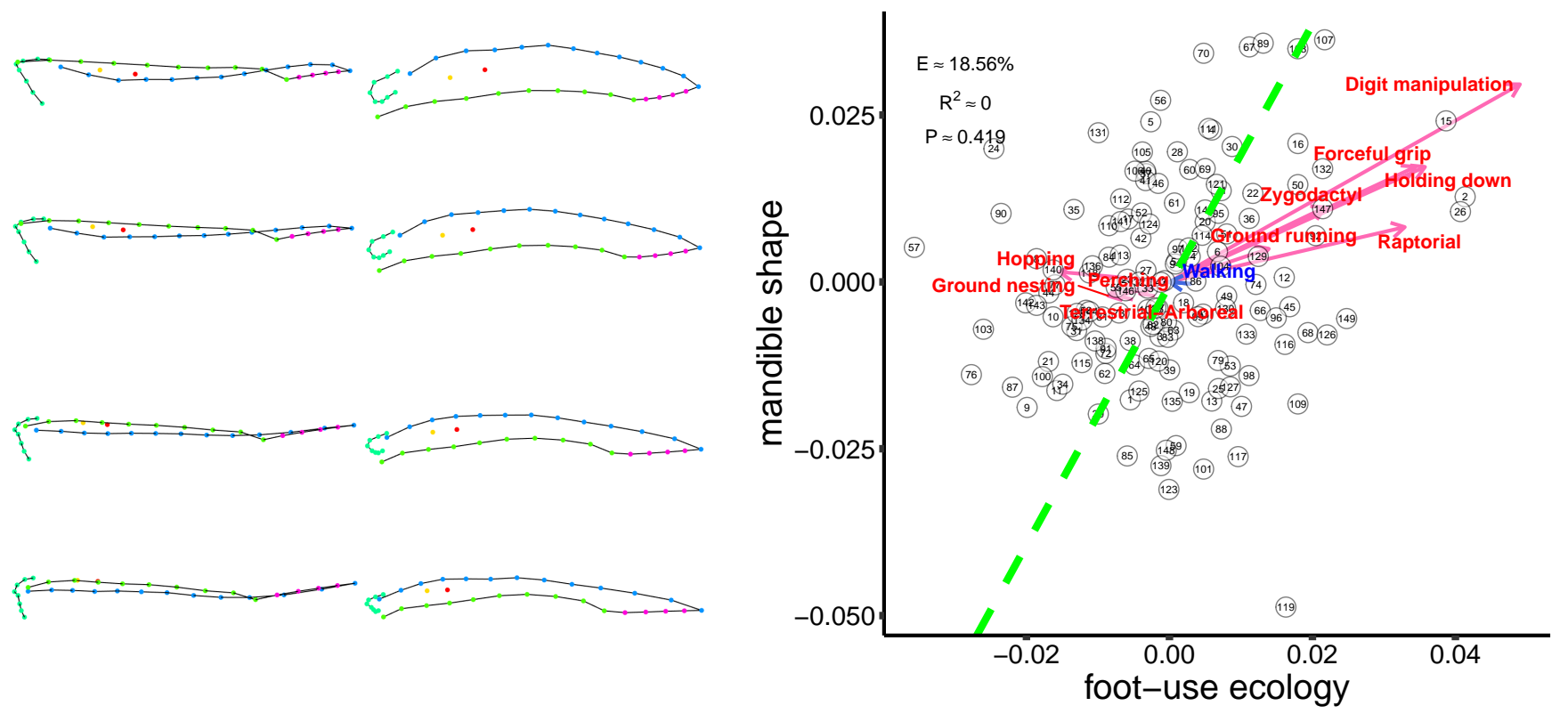

Supplementary Figure 15: Relationships for the second salience between hindlimb ecology and mandible morphology represented by p2BPLS analyses comparing shape to ecological trait blocks. Shape variation (y-axis) is illustrated using deviations from the mean shape derived from Procrustes superposition for the mandible in dorsal and lateral views. Arrows indicate selected ecological variables that change significantly across the sum of these axes ( $p$-value $<0.05)$. Red: Ecology increases in frequency away from the grand mean. Blue: Ecology increases in frequency towards the grand mean. Birds are represented by enumerated points (see Supplementary Table 1 for the species names) E represents the portion of explained variance along this salience. 


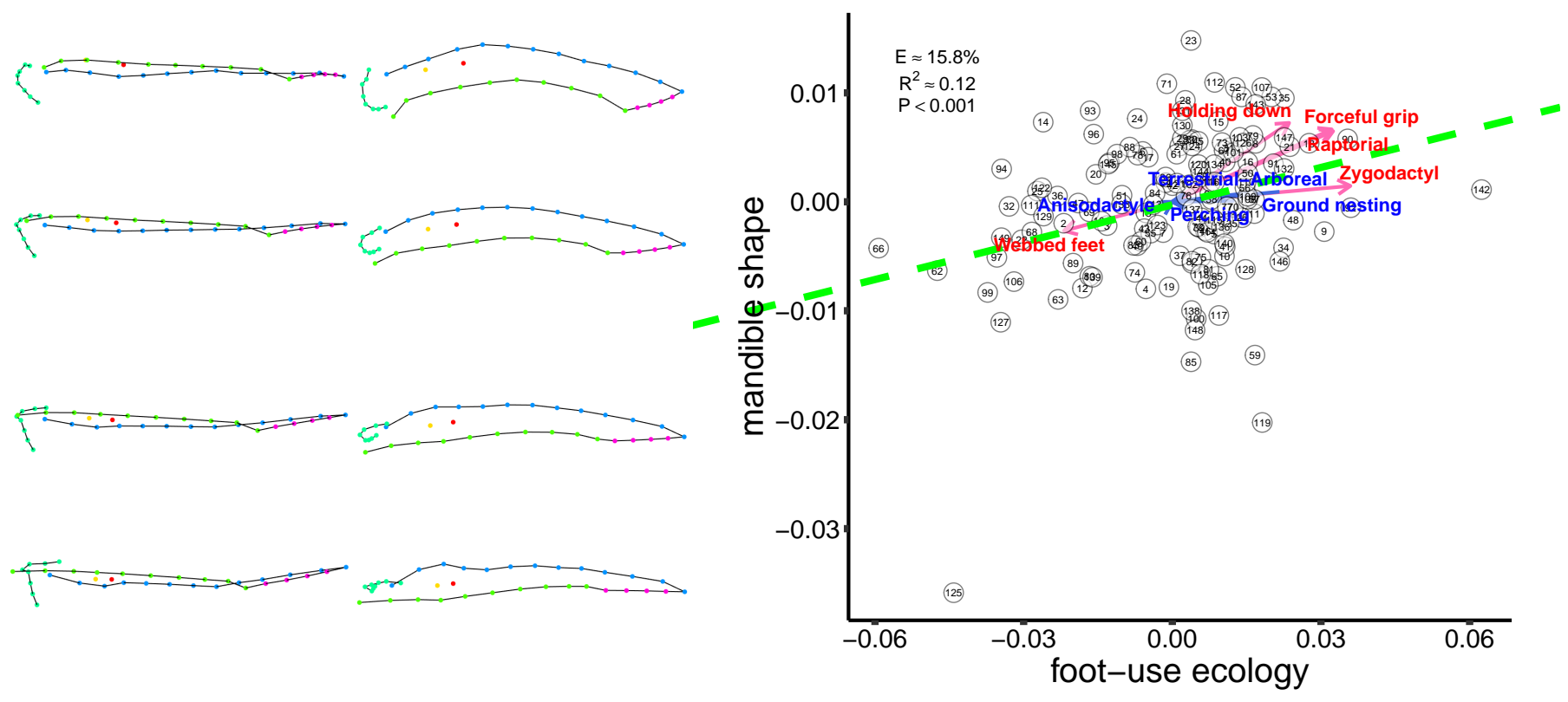

Supplementary Figure 16: Relationships for the third salience between hindlimb ecology and mandible morphology represented by p2BPLS analyses comparing shape to ecological trait blocks. Shape variation (y-axis) is illustrated using deviations from the mean shape derived from Procrustes superposition for the mandible in dorsal and lateral views. Arrows indicate selected ecological variables that change significantly across the sum of these axes $(p$-value $<0.05)$. Red: Ecology increases in frequency away from the grand mean. Blue: Ecology increases in frequency towards the grand mean. Birds are represented by enumerated points (see Supplementary Table 1 for the species names) E represents the portion of explained variance along this salience. 


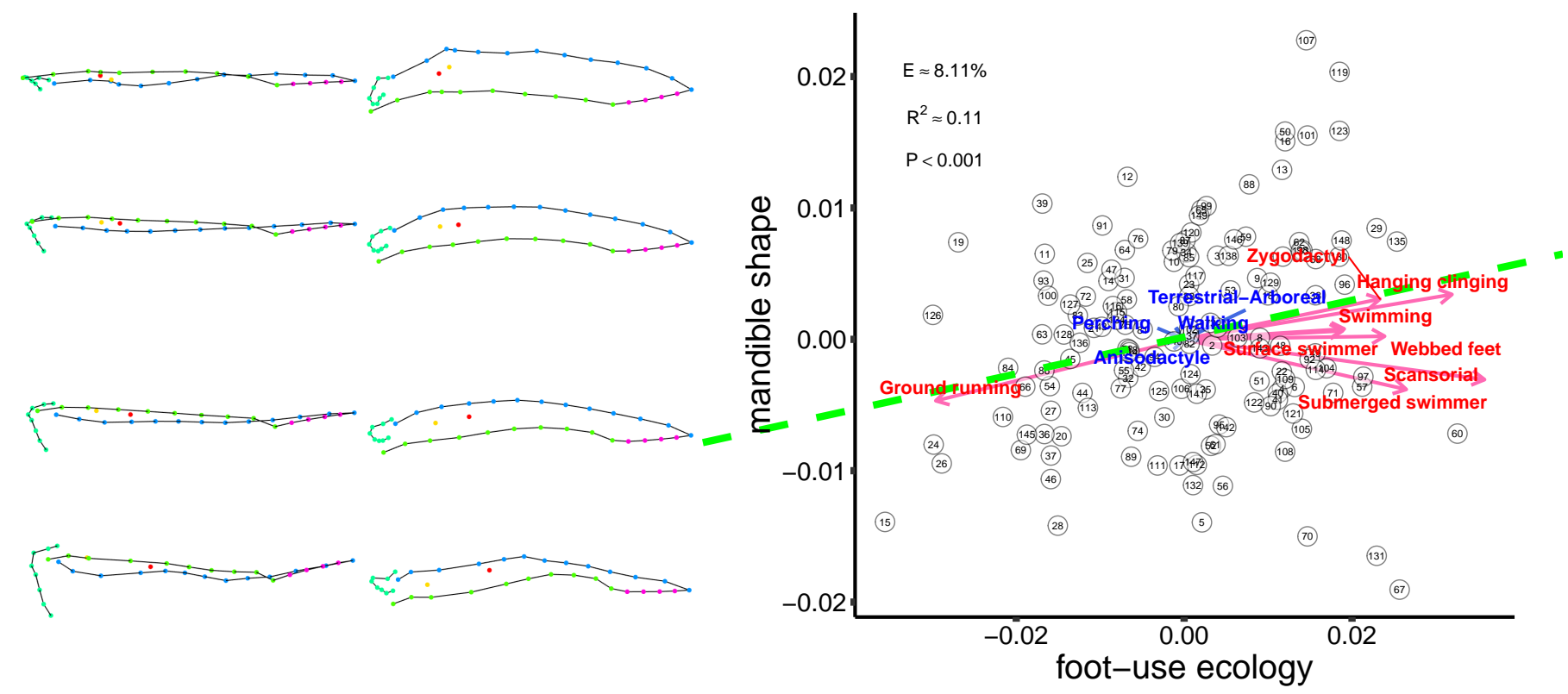

Supplementary Figure 17: Relationships for the fourth salience between hindlimb ecology and mandible morphology represented by p2BPLS analyses comparing shape to ecological trait blocks. Shape variation (y-axis) is illustrated using deviations from the mean shape derived from Procrustes superposition for the mandible in dorsal and lateral views. Arrows indicate selected ecological variables that change significantly across the sum of these axes ( $p$-value $<0.05)$. Red: Ecology increases in frequency away from the grand mean. Blue: Ecology increases in frequency towards the grand mean. Birds are represented by enumerated points (see Supplementary Table 1 for the species names) E represents the portion of explained variance along this salience. 


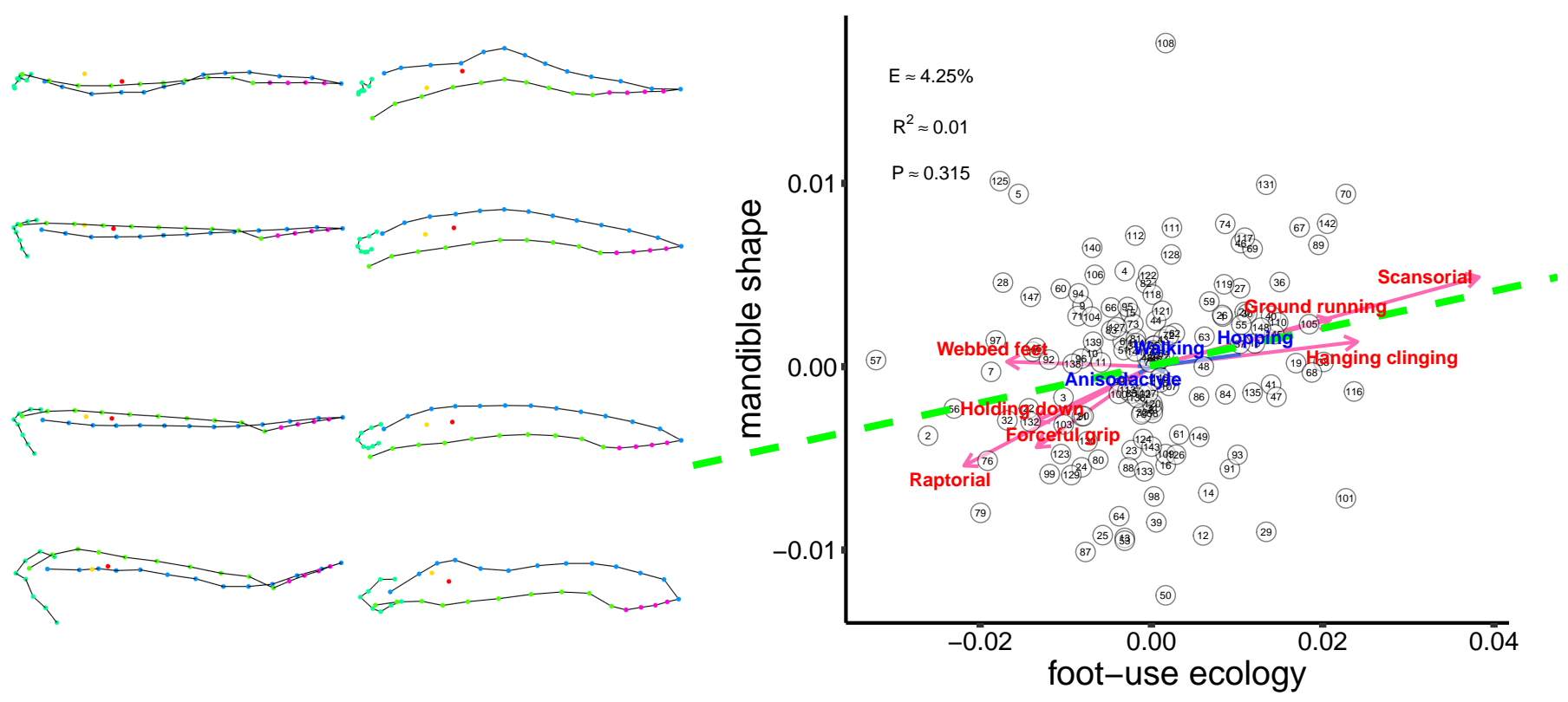

Supplementary Figure 18: Relationships for the fifth salience between hindlimb ecology and mandible morphology represented by p2BPLS analyses comparing shape to ecological trait blocks. Shape variation (y-axis) is illustrated using deviations from the mean shape derived from Procrustes superposition for the mandible in dorsal and lateral views. Arrows indicate selected ecological variables that change significantly across the sum of these axes $(p$-value $<0.05)$. Red: Ecology increases in frequency away from the grand mean. Blue: Ecology increases in frequency towards the grand mean. Birds are represented by enumerated points (see Supplementary Table 1 for the species names) E represents the portion of explained variance along this salience. 


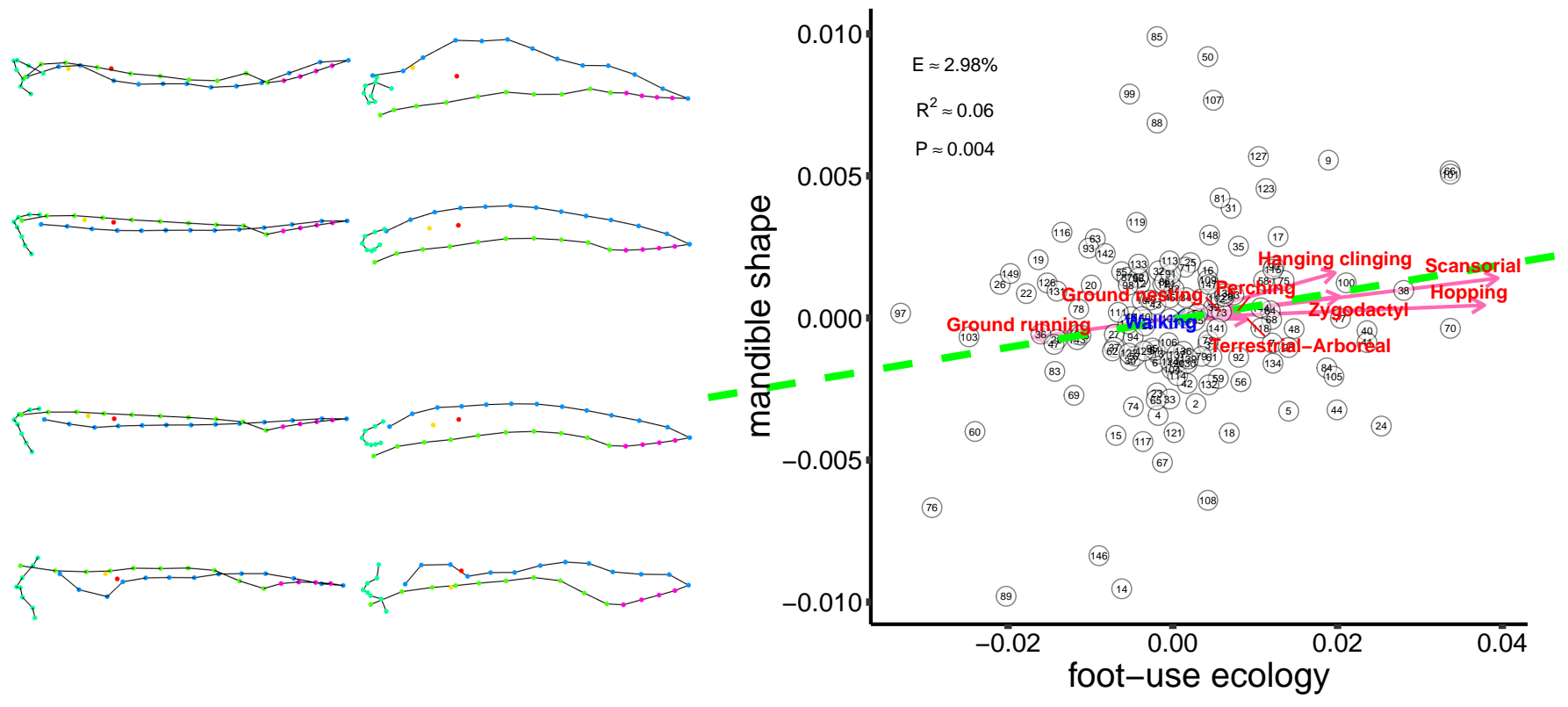

Supplementary Figure 19: Relationships for the sixth salience between hindlimb ecology and mandible morphology represented by p2BPLS analyses comparing shape to ecological trait blocks. Shape variation (y-axis) is illustrated using deviations from the mean shape derived from Procrustes superposition for the mandible in dorsal and lateral views. Arrows indicate selected ecological variables that change significantly across the sum of these axes $(p$-value $<0.05)$. Red: Ecology increases in frequency away from the grand mean. Blue: Ecology increases in frequency towards the grand mean. Birds are represented by enumerated points (see Supplementary Table 1 for the species names) E represents the portion of explained variance along this salience. 

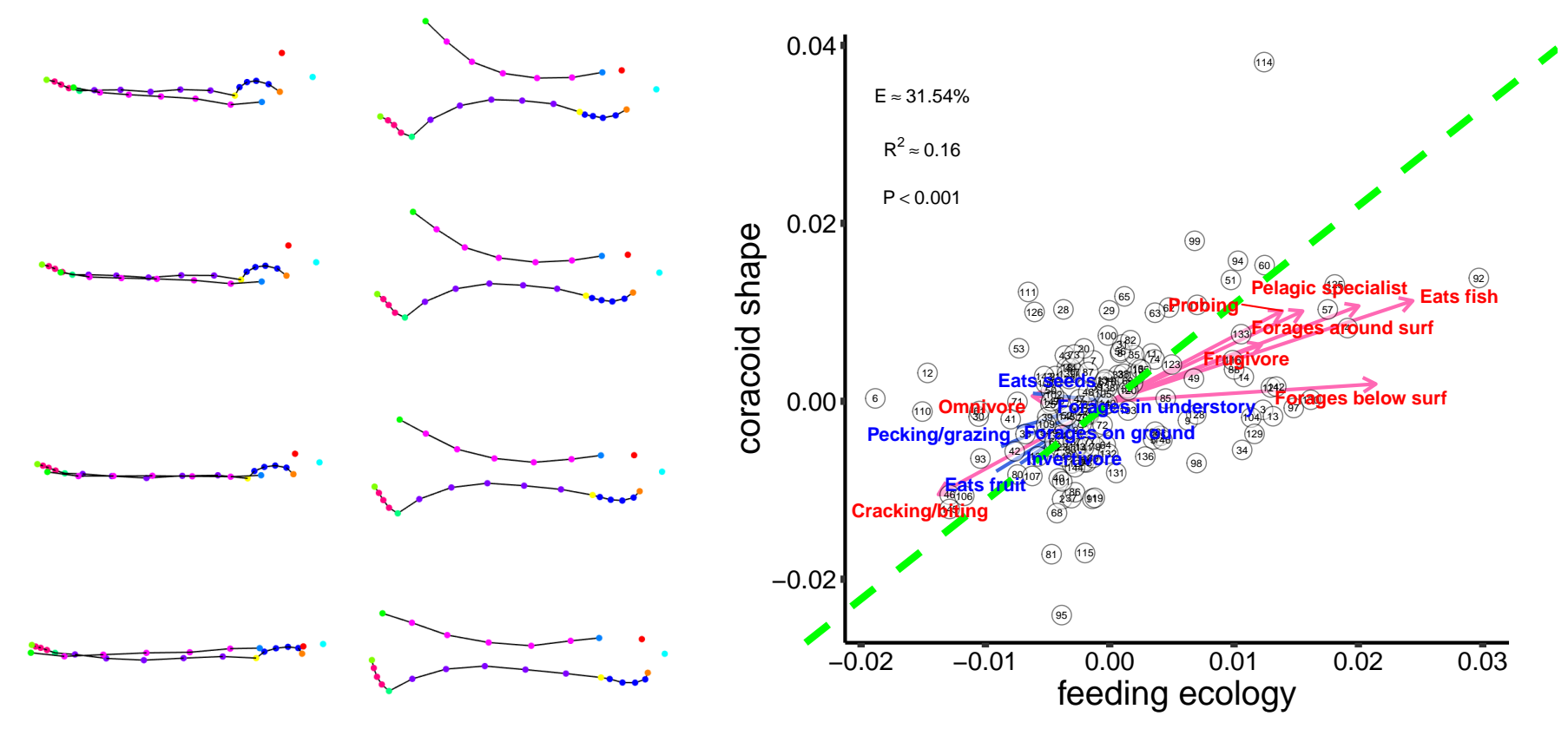

Supplementary Figure 20: Relationships for the first salience between feeding ecology and coracoid morphology represented by the first salience of p2BPLS analyses comparing shape to ecological trait blocks. Shape variation (y-axis) is illustrated using deviations from the mean shape derived from Procrustes superposition for the coracoid in dorsal and lateral views. Arrows indicate selected ecological variables that change significantly across the sum of these axes ( $p$-value $<0.05)$. Red: Ecology increases in frequency away from the grand mean. Blue: Ecology increases in frequency towards the grand mean. Birds are represented by enumerated points (see Supplementary Table 1 for the species names) E represents the portion of explained variance along this salience. 


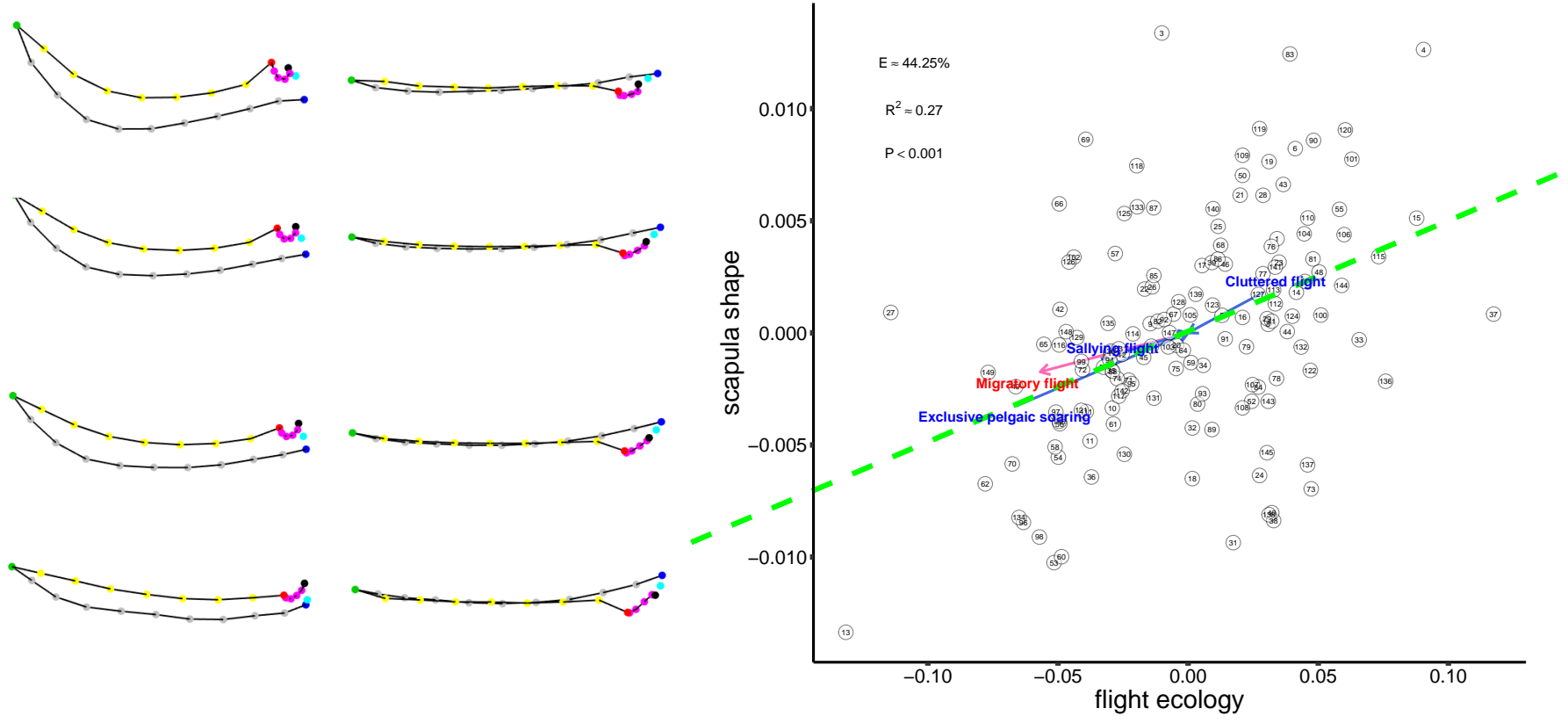

Supplementary Figure 21: Relationships for the first salience between flight ecology and scapula morphology represented by the first salience of p2BPLS analyses comparing shape to ecological trait blocks. Shape variation (y-axis) is illustrated using deviations from the mean shape derived from Procrustes superposition for the scapula in dorsal and lateral views. Arrows indicate selected ecological variables that change significantly across the sum of these axes ( $p$-value $<0.05)$. Red: Ecology increases in frequency away from the grand mean. Blue: Ecology increases in frequency towards the grand mean. Birds are represented by enumerated points (see Supplementary Table 1 for the species names) E represents the portion of explained variance along this salience. 


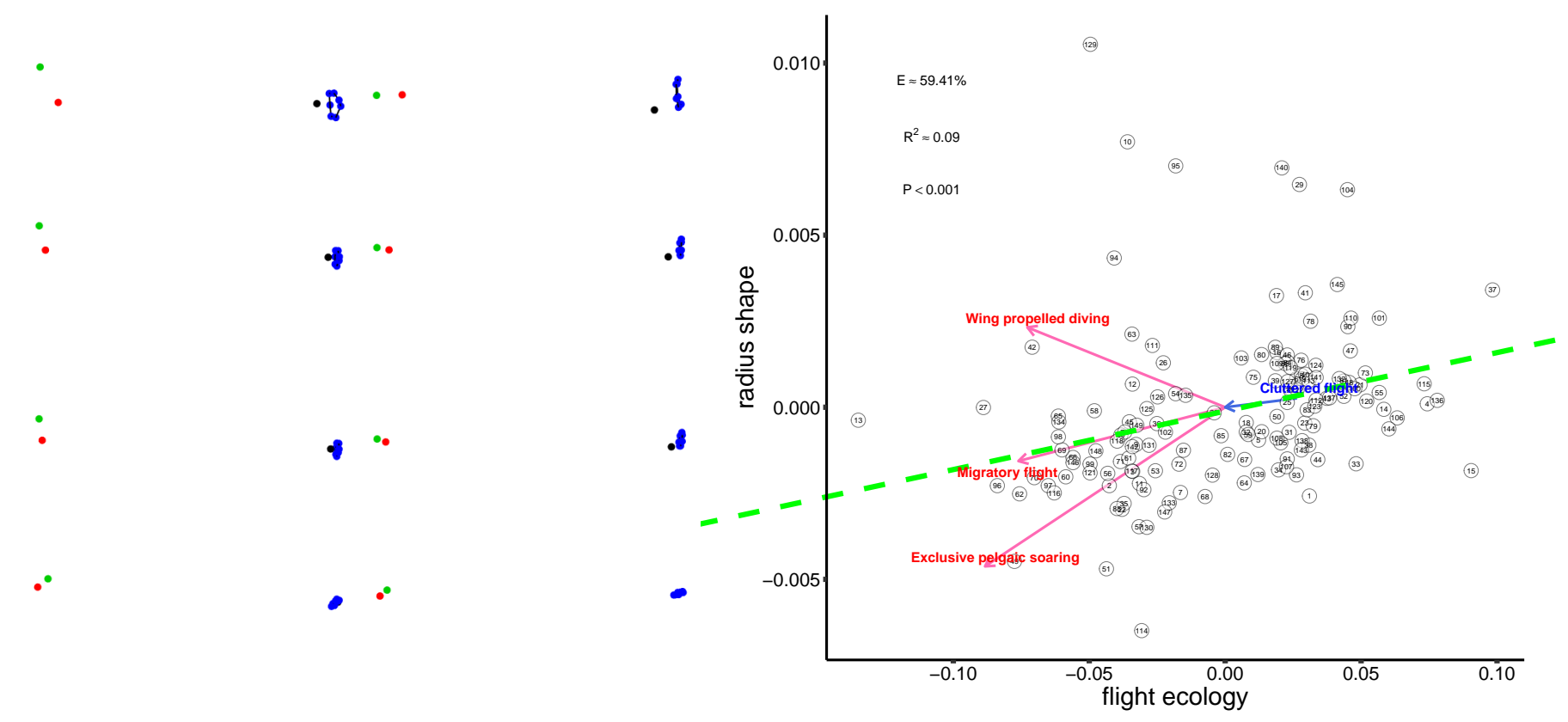

Supplementary Figure 22: Relationships for the first salience between flight ecology and radius morphology represented by the first salience of p2BPLS analyses comparing shape to ecological trait blocks. Shape variation (y-axis) is illustrated using deviations from the mean shape derived from Procrustes superposition for the sternum in dorsal and lateral views. Arrows indicate selected ecological variables that change significantly across the sum of these axes ( $p$-value $<0.05)$. Red: Ecology increases in frequency away from the grand mean. Blue: Ecology increases in frequency towards the grand mean. Birds are represented by enumerated points (see Supplementary Table 1 for the species names) E represents the portion of explained variance along this salience. 

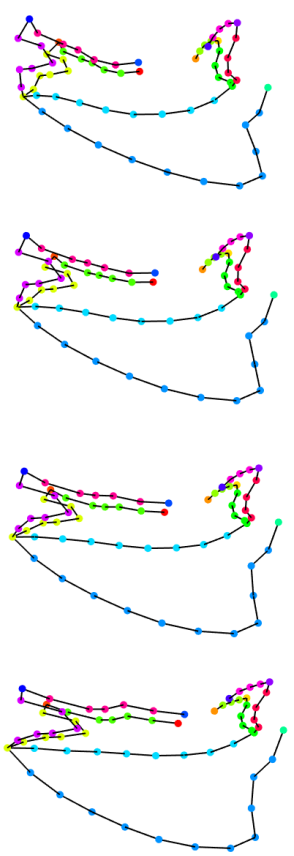
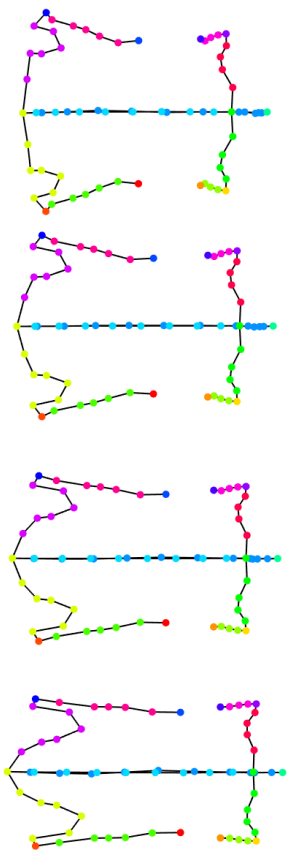

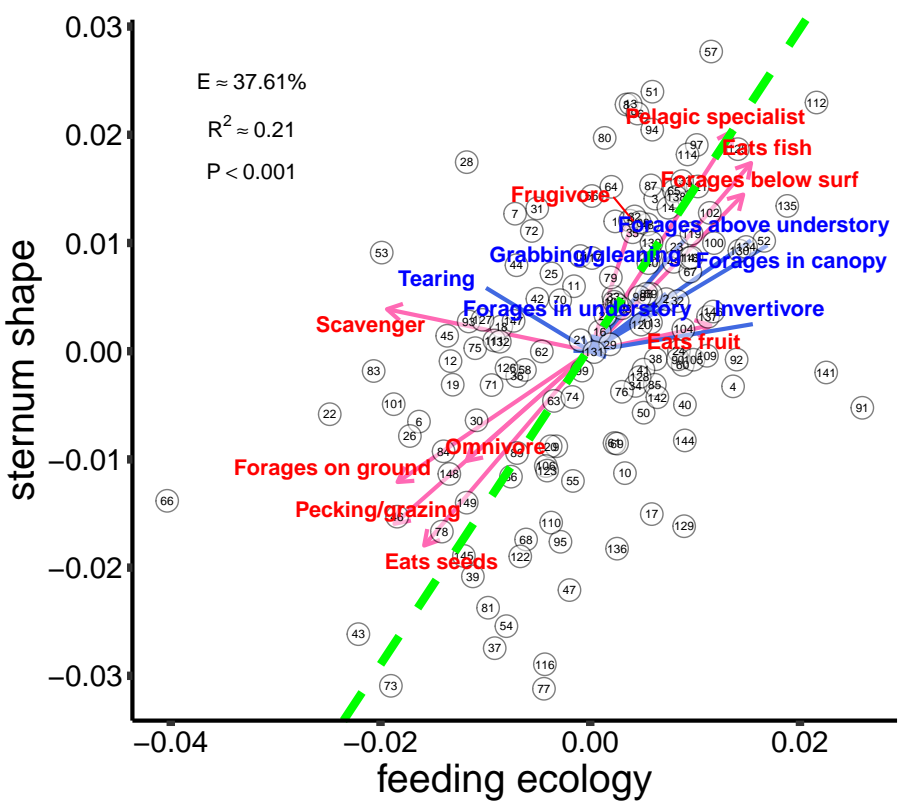

Supplementary Figure 23: Relationships for the first salience between feeding ecology and sternum morphology represented by the first salience of p2BPLS analyses comparing shape to ecological trait blocks. Shape variation (y-axis) is illustrated using deviations from the mean shape derived from Procrustes superposition for the sternum in dorsal and lateral views. Arrows indicate selected ecological variables that change significantly across the sum of these axes ( $p$-value $<0.05)$. Red: Ecology increases in frequency away from the grand mean. Blue: Ecology increases in frequency towards the grand mean. Birds are represented by enumerated points (see Supplementary Table 1 for the species names) E represents the portion of explained variance along this salience. 

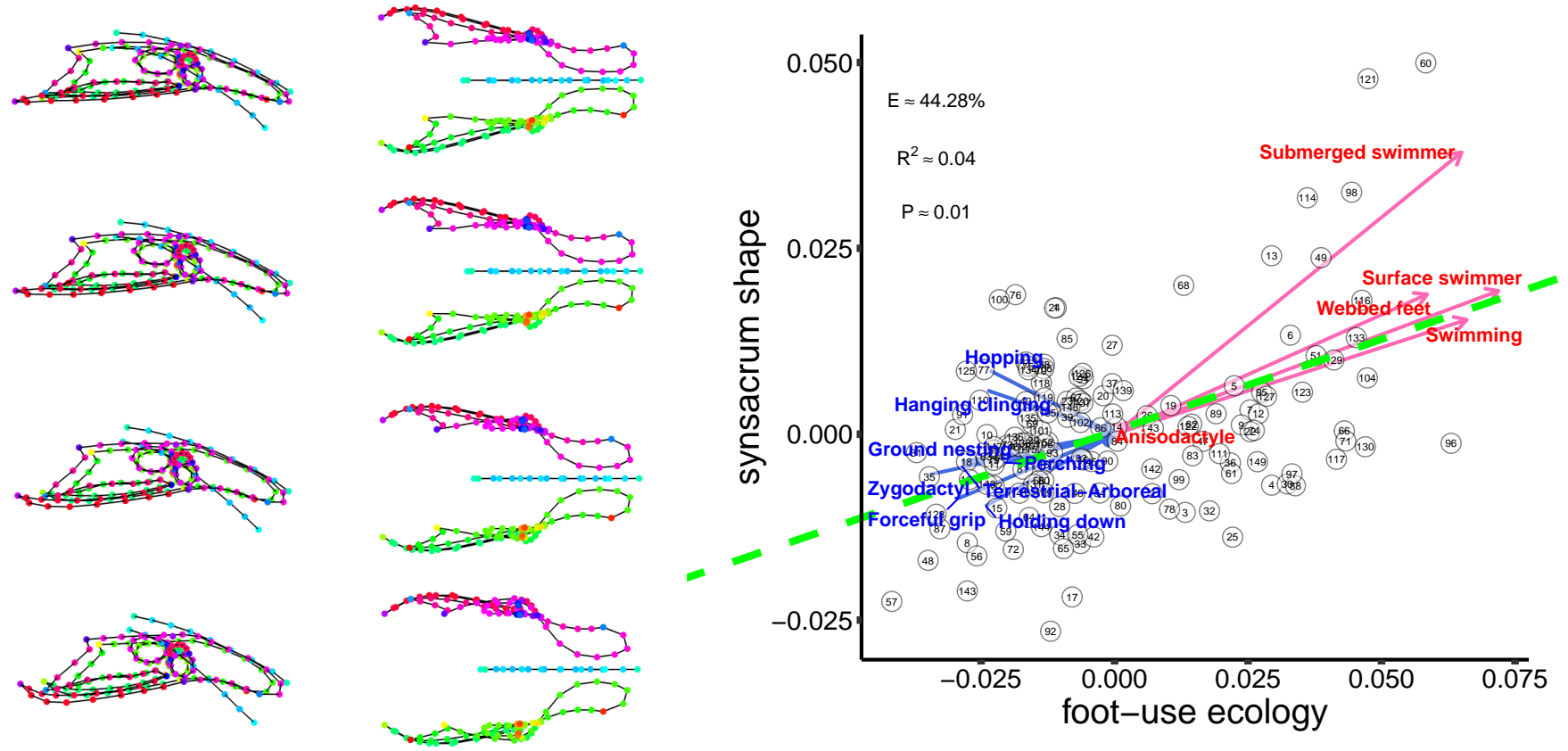

Supplementary Figure 24: Relationships for the first salience between hindlimb ecology and synsacrum morphology represented by the first salience of p2BPLS analyses comparing shape to ecological trait blocks. Shape variation (y-axis) is illustrated using deviations from the mean shape derived from Procrustes superposition for the synsacrum in dorsal and lateral views. Arrows indicate selected ecological variables that change significantly across the sum of these axes $(p$-value $<0.05)$. Red: Ecology increases in frequency away from the grand mean. Blue: Ecology increases in frequency towards the grand mean. Birds are represented by enumerated points (see Supplementary Table 1 for the species names) E represents the portion of explained variance along this salience. 

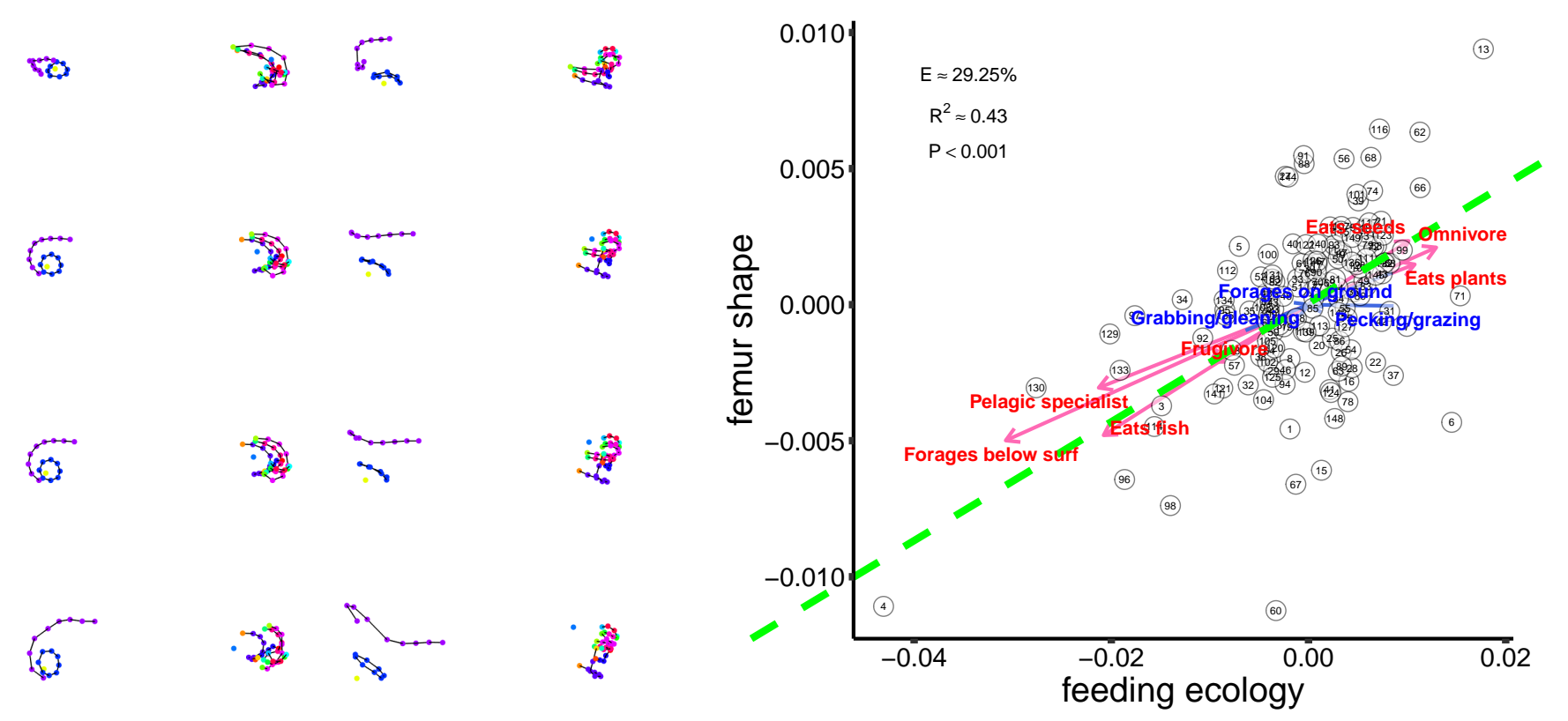

Supplementary Figure 25: Relationships for the first salience between feeding ecology and femur morphology represented by the first salience of p2BPLS analyses comparing shape to ecological trait blocks. Shape variation (y-axis) is illustrated using deviations from the mean shape derived from Procrustes superposition for the femur in dorsal and lateral views. Arrows indicate selected ecological variables that change significantly across the sum of these axes ( $p$-value $<0.05)$. Red: Ecology increases in frequency away from the grand mean. Blue: Ecology increases in frequency towards the grand mean. Birds are represented by enumerated points (see Supplementary Table 1 for the species names) E represents the portion of explained variance along this salience. 


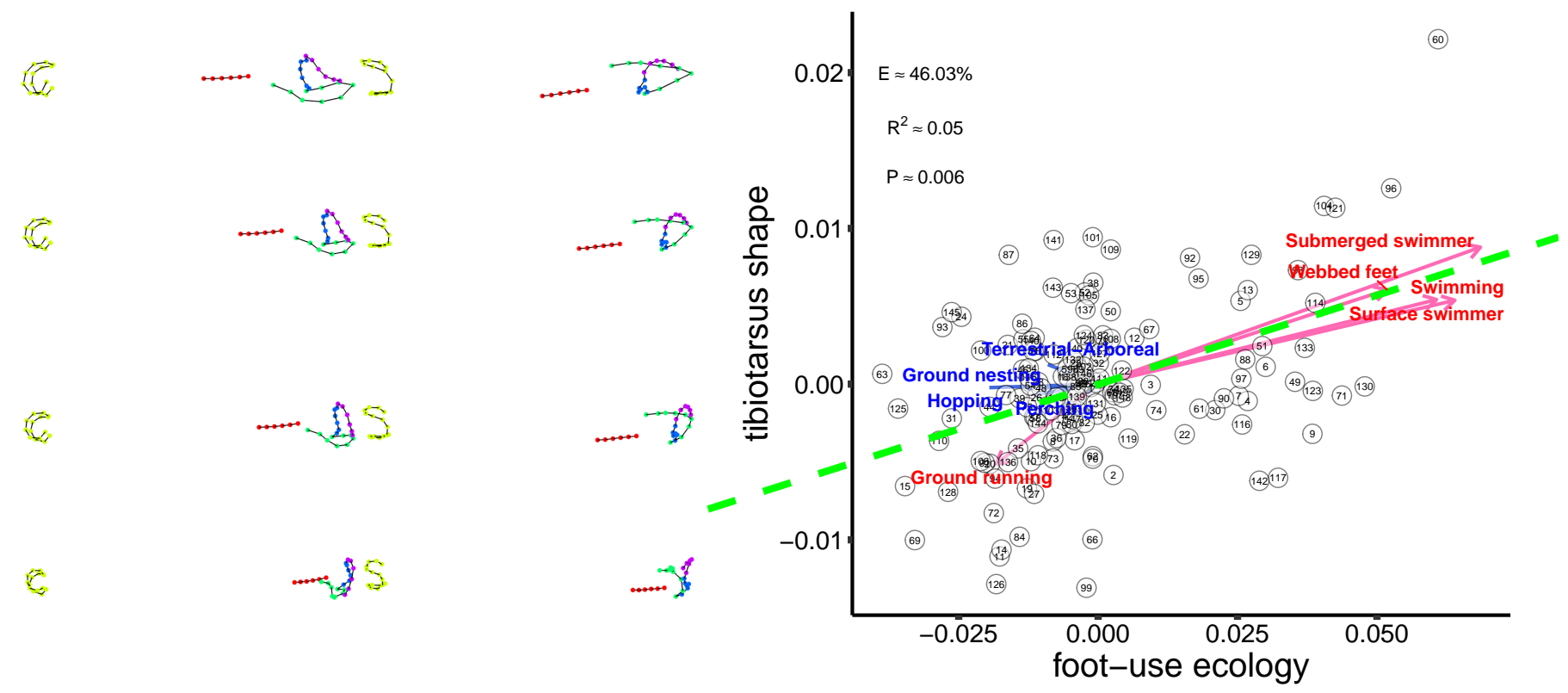

Supplementary Figure 26: Relationships for the first salience between hindlimb ecology and tibiotarsus morphology represented by the first salience of p2BPLS analyses comparing shape to ecological trait blocks. Shape variation (y-axis) is illustrated using deviations from the mean shape derived from Procrustes superposition for the tibiotarsus in dorsal and lateral views. Arrows indicate selected ecological variables that change significantly across the sum of these axes $(p$-value $<0.05)$. Red: Ecology increases in frequency away from the grand mean. Blue: Ecology increases in frequency towards the grand mean. Birds are represented by enumerated points (see Supplementary Table 1 for the species names) E represents the portion of explained variance along this salience. 


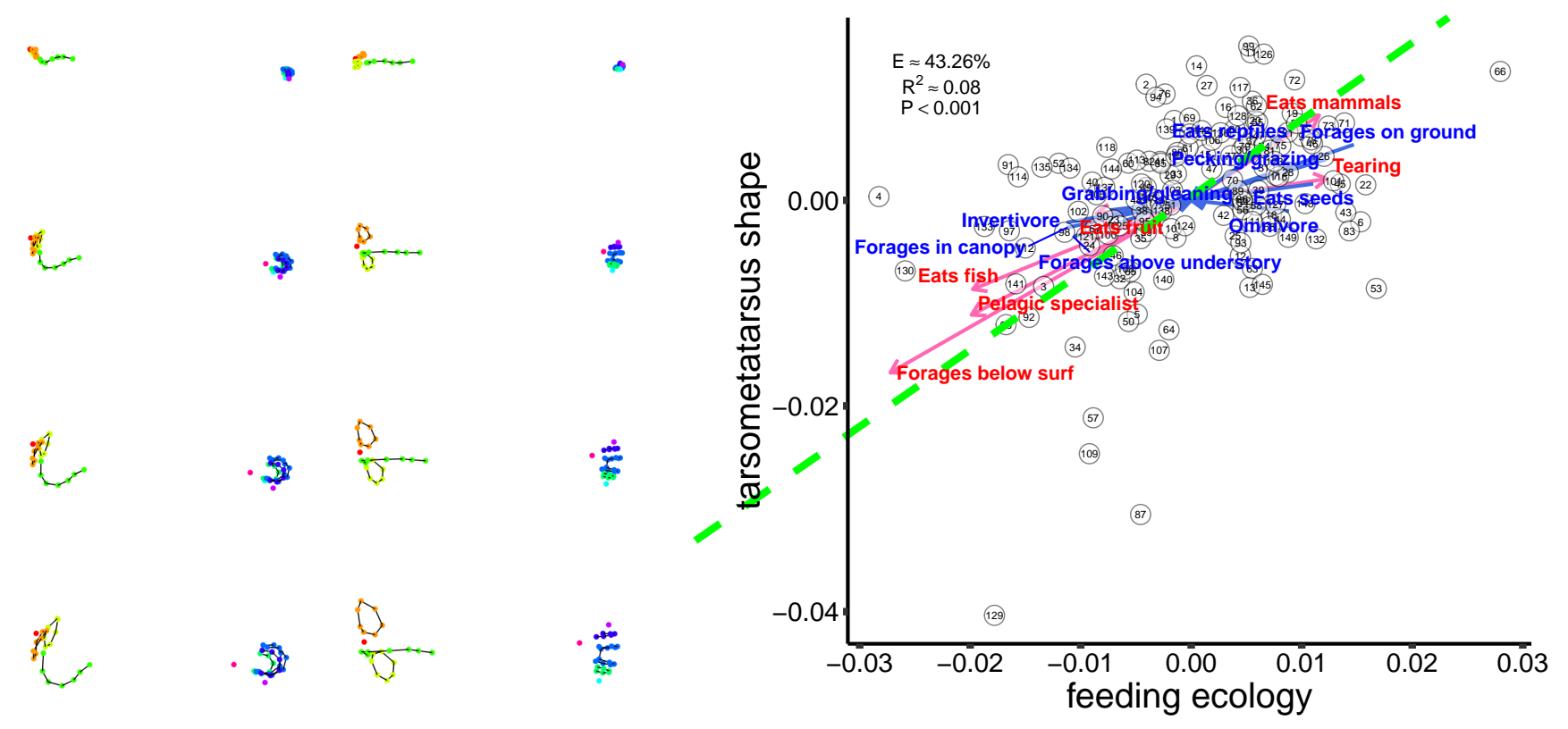

Supplementary Figure 27: Relationships for the first salience between feeding ecology and tarsometatarsus morphology represented by the first salience of p2BPLS analyses comparing shape to ecological trait blocks. Shape variation (y-axis) is illustrated using deviations from the mean shape derived from Procrustes superposition for the tarsometatarsus in dorsal and lateral views. Arrows indicate selected ecological variables that change significantly across the sum of these axes $(p$-value $<0.05)$. Red: Ecology increases in frequency away from the grand mean. Blue: Ecology increases in frequency towards the grand mean. Birds are represented by enumerated points (see Supplementary Table 1 for the species names) E represents the portion of explained variance along this salience. 


\section{PCoA spaces}
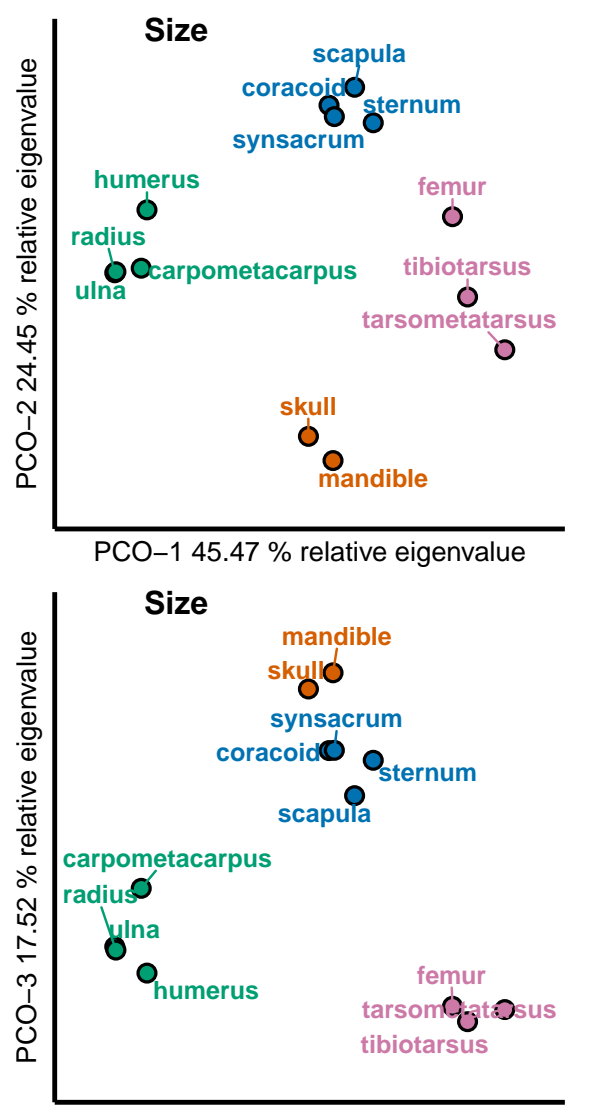

PCO-1 $45.47 \%$ relative eigenvalue
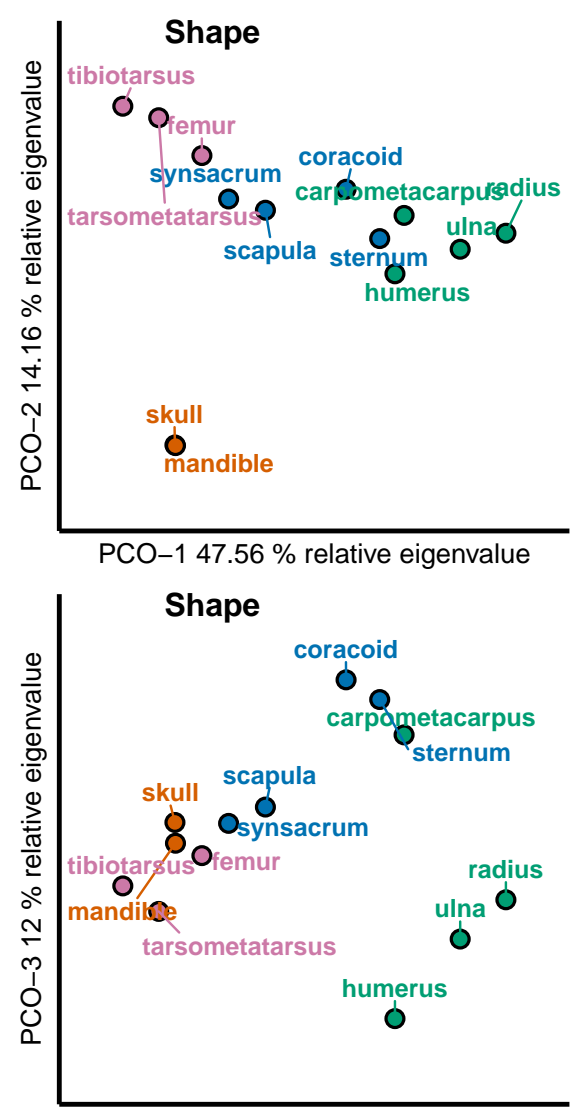

PCO-1 $47.56 \%$ relative eigenvalue
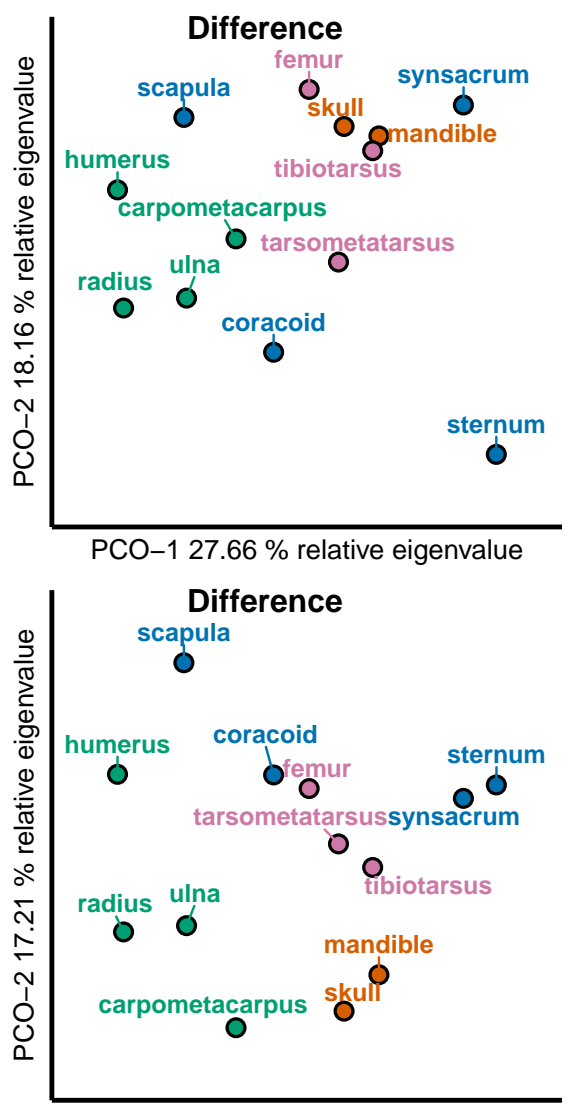

PCO-127.66 \% relative eigenvalue

Supplementary Figure 28: Patterns of evolutionary integration across the bird skeleton, presented as PCoA spaces, computed from distance matrices derived from heat-maps in Figure 2 (main manuscript). Bones are grouped by colour into body regions. 


\section{Raw effect sizes}

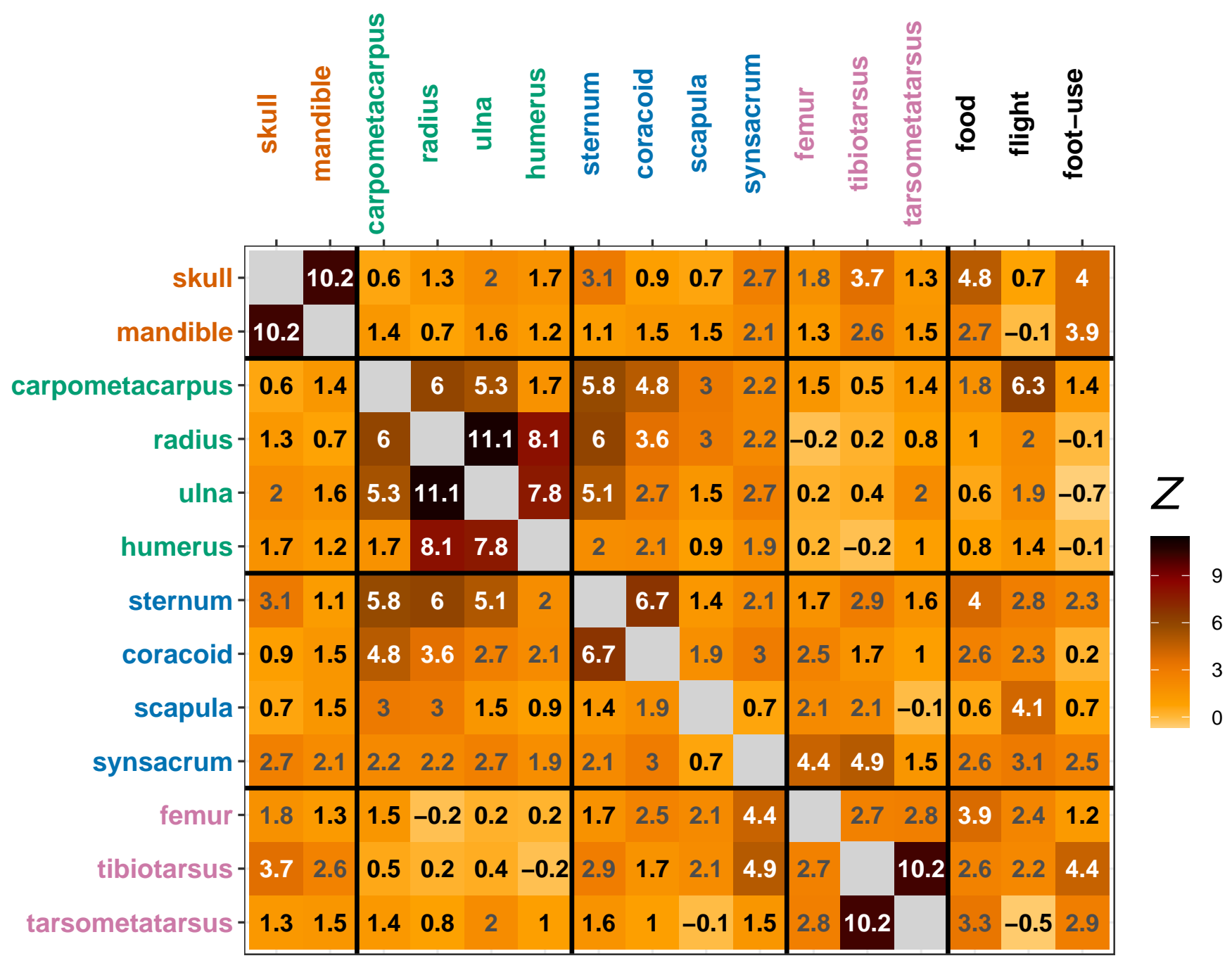

Supplementary Figure 29: Effect sizes of pairwise covariances of skeletal shapes across all birds $(\mathrm{N}=149)$. Black, grey and white fonts denote $p$-values of $>0.05,<0.05$ and $<0.005$, respectively. 


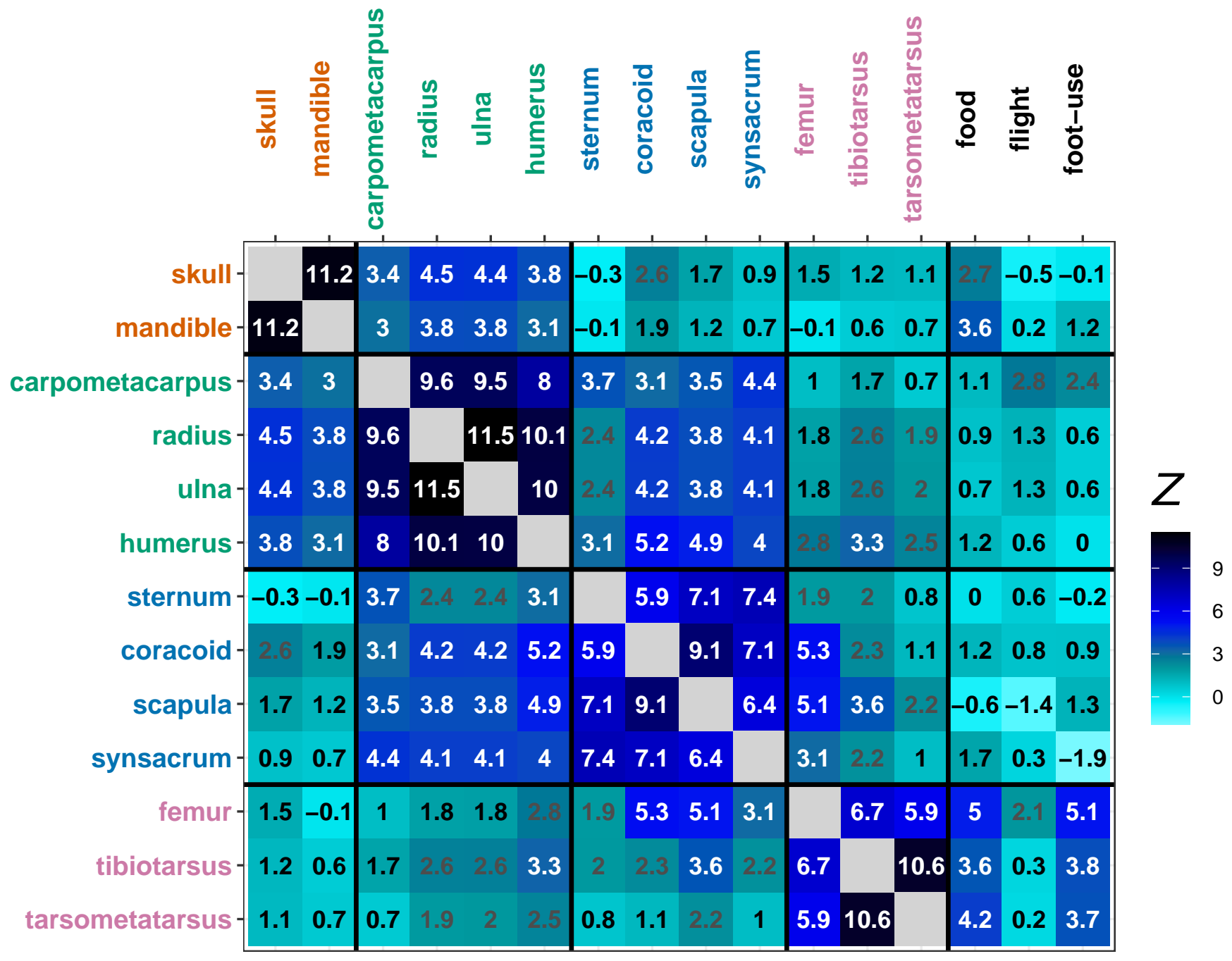

Supplementary Figure 30: Effect sizes of pairwise covariances of skeletal sizes across all birds $(\mathrm{N}=149)$. Black, grey and white fonts denote $p$-values of $>0.05,<0.05$ and $<0.005$, respectively. 


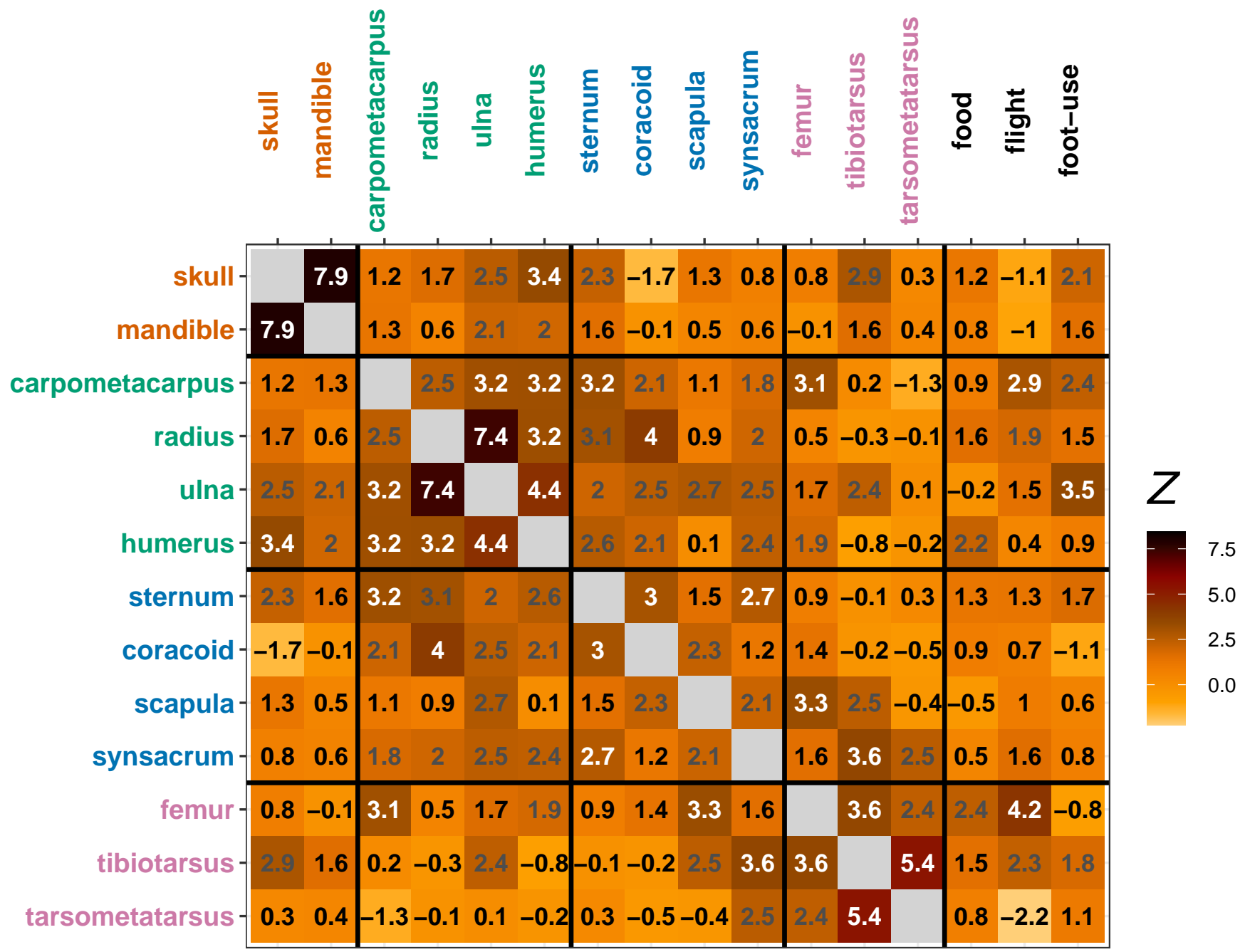

Supplementary Figure 31: Effect sizes of pairwise covariances of skeletal shapes across Telluraves $(\mathrm{N}=72)$. Black, grey and white fonts denote $p$-values of $>0.05,<0.05$ and $<0.005$, respectively. 


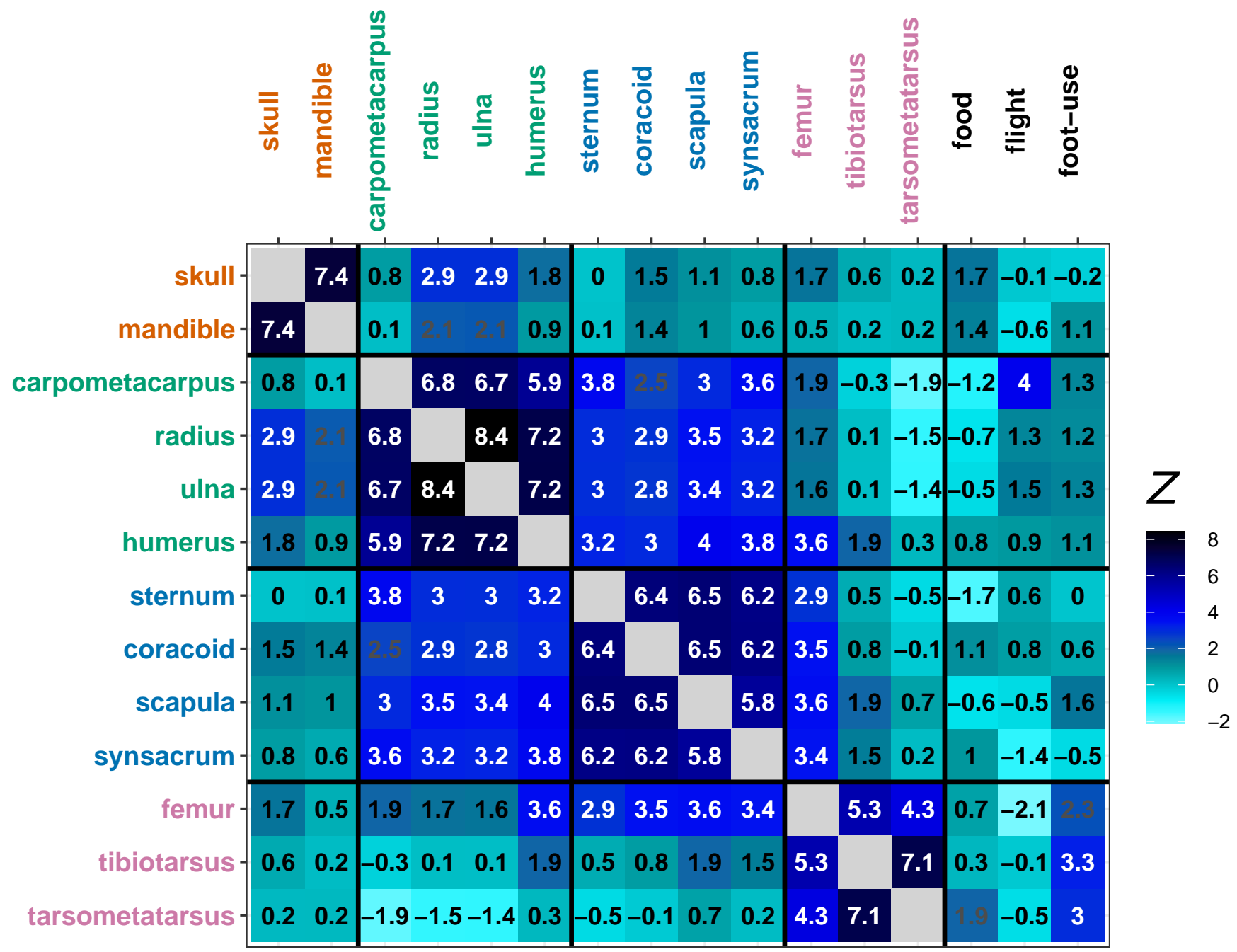

Supplementary Figure 32: Effect sizes of pairwise covariances of skeletal sizes across Telluraves $(\mathrm{N}=72)$. Black, grey and white fonts denote $p$-values of $>0.05,<0.05$ and $<0.005$, respectively. 


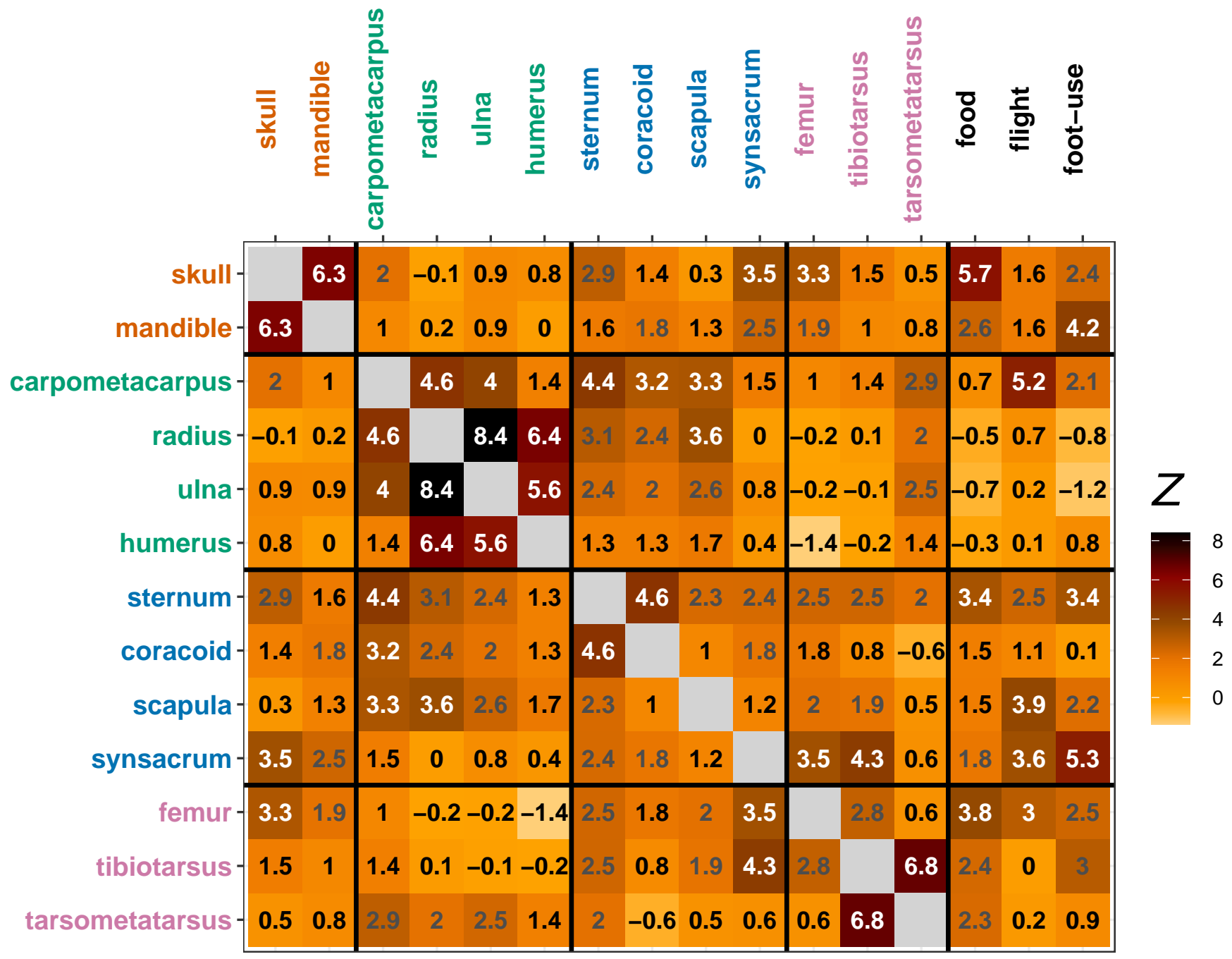

Supplementary Figure 33: Effect sizes of pairwise covariances of skeletal shapes across non-Telluraves $(\mathrm{N}=77)$. Black, grey and white fonts denote $p$-values of $>0.05,<0.05$ and $<0.005$, respectively. 


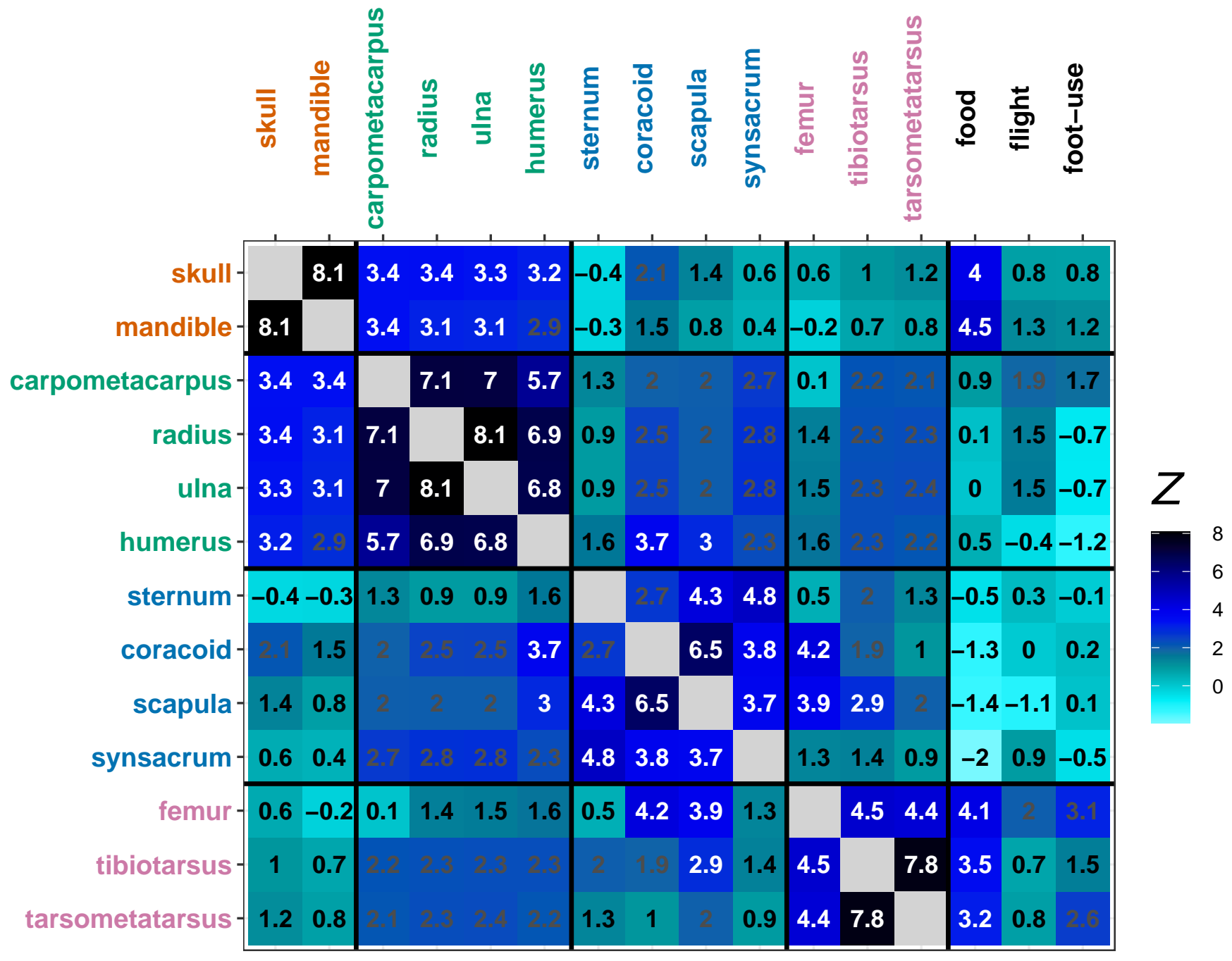

Supplementary Figure 34: Effect sizes of pairwise covariances of skeletal sizes across non-Telluraves $(\mathrm{N}=77)$. Black, grey and white fonts denote $p$-values of $>0.05,<0.05$ and $<0.005$, respectively. 


\section{Specimen list}

\begin{tabular}{|c|c|c|c|c|c|c|}
\hline \# & Genus & Species & Family & Order & $\begin{array}{l}\text { Specimen } \\
\text { number }\end{array}$ & $\begin{array}{l}\text { Prum } \\
\text { name }\end{array}$ \\
\hline 1 & Acanthisitta & chloris & Acanthisittidae & Passeriformes & $\begin{array}{l}\text { YPM } \\
125219\end{array}$ & Acanthisitta \\
\hline 2 & Accipiter & nisus & Accipitridae & Accipitriformes & $\begin{array}{l}\text { NHMUK } \\
\text { S/1982.149.1 }\end{array}$ & Accipiter \\
\hline 3 & Alcedo & atthis & Alcedinidae & Coraciiformes & $\begin{array}{l}\text { NHMUK } \\
\text { S/1994.7.1 }\end{array}$ & Alcedo \\
\hline 4 & Anas & discors & Anatidae & Anseriformes & $\begin{array}{l}\text { NHMUK } \\
\text { S/2001.41.5 }\end{array}$ & Anas \\
\hline 5 & Anhinga & anhinga & Anhingidae & Suliformes & $\begin{array}{l}\text { FMNH } \\
491374\end{array}$ & Anhinga \\
\hline 6 & Anser & fabalis & Anatidae & Anseriformes & $\begin{array}{l}\text { NHMUK } \\
\text { 1895.2.6.9 }\end{array}$ & Anser \\
\hline 7 & Anseranas & semipalmata & Anseranatidae & Anseriformes & $\begin{array}{l}\text { NHMUK } \\
1852.7 .22 .1\end{array}$ & Anseranas \\
\hline 8 & Apaloderma & narino & Trogonidae & Trogoniformes & $\begin{array}{l}\text { FMNH } \\
290897\end{array}$ & Apaloderma \\
\hline 9 & Aramus & guarauna & Aramidae & Gruiformes & $\begin{array}{l}\text { FMNH } \\
376078\end{array}$ & Aramus \\
\hline 10 & Archilochus & colubris & Trochilidae & Apodiformes & $\begin{array}{l}\text { FMNH } \\
484738\end{array}$ & Archilochus \\
\hline 11 & Ardea & alba & Ardeidae & Pelecaniformes & $\begin{array}{l}\text { UMZC } \\
338 . \mathrm{H}\end{array}$ & Ardea \\
\hline 12 & Ardeotis & kori & Otididae & Otidiformes & $\begin{array}{l}\text { UMMZ } \\
210444\end{array}$ & Ardeotis \\
\hline 13 & Arenaria & interpres & Scolopacidae & Charadriiformes & $\begin{array}{l}\text { FMNH } \\
313992\end{array}$ & Arenaria \\
\hline 14 & Aythya & ferina & Anatidae & Anseriformes & $\begin{array}{l}\text { NMHUK } \\
1851.12 .23 .15\end{array}$ & Aythya \\
\hline 15 & Balaeniceps & rex & Balaenicipitidae & Pelecaniformes & $\begin{array}{l}\text { NHMUK } \\
\text { S/1952.1.100 }\end{array}$ & Balaeniceps \\
\hline 16 & Balearica & pavonina & Gruidae & Gruiformes & $\begin{array}{l}\text { NHMUK } \\
1859.10 .26 .5\end{array}$ & Balearica \\
\hline 17 & Barnardius & zonarius & Psittaculidae & Psittaciformes & $\begin{array}{l}\text { NHMUK } \\
\text { S/1983.5.1 }\end{array}$ & Barnardius \\
\hline 18 & Bonasa & umbellus & Phasianidae & Galliformes & $\begin{array}{l}\text { FMNH } \\
348972\end{array}$ & Bonasa \\
\hline 19 & Виссо & capensis & Bucconidae & Piciformes & $\begin{array}{l}\text { FMNH } \\
330305\end{array}$ & Bucco \\
\hline 20 & Bucorvus & abyssinicus & Bucorvidae & Bucerotiformes & $\begin{array}{l}\text { NHMUK } \\
\text { S/2006.31.20 }\end{array}$ & Bucorvus \\
\hline 1 & Burhinus & senegalensis & Burhinidae & Charadriiformes & $\begin{array}{l}\text { FMNH } \\
313704\end{array}$ & Burhinus \\
\hline
\end{tabular}




\begin{tabular}{|c|c|c|c|c|c|c|}
\hline 22 & Buteo & rufofuscus & Accipitridae & Accipitriformes & $\begin{array}{l}\text { NHMUK } \\
1862.1 .18 .1\end{array}$ & Buteo \\
\hline 23 & Calandrella & cinerea & Alaudidae & Passeriformes & $\begin{array}{l}\text { NHMUK } \\
\text { S/1961.13.34 }\end{array}$ & Calandrella \\
\hline 24 & Calyptomena & viridis & Calyptomenidae & Passeriformes & $\begin{array}{l}\text { NHMUK } \\
\text { S/1969.1.70 }\end{array}$ & Calyptomena \\
\hline 25 & Capito & niger & Capitonidae & Piciformes & $\begin{array}{l}\text { FMNH } \\
321049\end{array}$ & Capito \\
\hline 26 & Caprimulgus & macrurus & Caprimulgidae & Caprimulgiformes & $\begin{array}{l}\text { FMNH } \\
392245\end{array}$ & Caprimulgus \\
\hline 27 & Caracara & cheriway & Falconidae & Falconiformes & $\begin{array}{l}\text { UMMZ } \\
133664\end{array}$ & Caracara \\
\hline 28 & Cariama & cristata & Cariamidae & Cariamiformes & $\begin{array}{l}\text { FMNH } \\
105653\end{array}$ & Cariama \\
\hline 29 & Cathartes & burrovianus & Cathartidae & Accipitriformes & $\begin{array}{l}\text { UMMZ } \\
227466\end{array}$ & Cathartes \\
\hline 30 & Ceratopipra & erythrocephala & Pipridae & Passeriformes & $\begin{array}{l}\text { UMMZ } \\
157210\end{array}$ & Pipra \\
\hline 31 & Chaetura & pelagica & Apodidae & Apodiformes & $\begin{array}{l}\text { UMMZ } \\
157689\end{array}$ & Chaetura \\
\hline 32 & Charadrius & vociferus & Charadriidae & Charadriiformes & $\begin{array}{l}\text { FMNH } \\
470173\end{array}$ & Charadrius \\
\hline 33 & Chauna & chavaria & Anhimidae & Anseriformes & $\begin{array}{l}\text { OUMNH } \\
23790\end{array}$ & Chauna \\
\hline 34 & Chelidoptera & tenebrosa & Bucconidae & Piciformes & $\begin{array}{l}\text { YPM } \\
114404\end{array}$ & Chelidoptera \\
\hline 35 & Choloroceryle & amazona & Alcedinidae & Coraciiformes & $\begin{array}{l}\text { UMMZ } \\
209261\end{array}$ & Chloroceryle \\
\hline 36 & Chordeiles & minor & Caprimulgidae & Caprimulgiformes & $\begin{array}{l}\text { UMMZ } \\
233923\end{array}$ & Chordeiles \\
\hline 37 & Chroicocephalus & novaehollandiae & Laridae & Charadriiformes & $\begin{array}{l}\text { UMZC } \\
274 . \mathrm{C}\end{array}$ & Chroicocephalus \\
\hline 38 & Chunga & burmeisteri & Cariamidae & Cariamiformes & $\begin{array}{l}\text { FMNH } \\
106731\end{array}$ & Chunga \\
\hline 39 & Climacteris & melanura & Climacteridae & Passeriformes & $\begin{array}{l}\text { UMMZ } \\
214303\end{array}$ & Climacteris \\
\hline 40 & Colinus & virginianus & Odontophoridae & Galliformes & $\begin{array}{l}\text { FMNH } \\
105065\end{array}$ & Colinus \\
\hline 41 & Colius & macrourus & Coliidae & Coliiformes & $\begin{array}{l}\text { FMNH } \\
368959\end{array}$ & Urocolius \\
\hline 42 & Colius & striatus & Coliidae & Coliiformes & $\begin{array}{l}\text { FMNH } \\
384817\end{array}$ & Colius \\
\hline 43 & Columba & palumbus & Columbidae & Columbiformes & $\begin{array}{l}\text { UMZC } \\
409 . A\end{array}$ & Columba \\
\hline 44 & Columbina & minutas & Columbidae & Columbiformes & $\begin{array}{l}\text { FMNH } \\
289160\end{array}$ & Columbina \\
\hline 45 & Coracias & benghalensis & Coraciidae & Coraciiformes & $\begin{array}{l}\text { NHMUK } \\
\text { S/1987.19.15 }\end{array}$ & Coracias \\
\hline
\end{tabular}




\begin{tabular}{|c|c|c|c|c|c|c|}
\hline 46 & Corvus & brachyrhynchos & Corvidae & Passeriformes & $\begin{array}{l}\text { FMNH } \\
441515\end{array}$ & Corvus \\
\hline 47 & Crax & mitu & Cracidae & Galliformes & $\begin{array}{l}\text { FMNH } \\
320386\end{array}$ & Crax \\
\hline 48 & Cryptopipo & holochlora & Pipridae & Passeriformes & $\begin{array}{l}\text { FMNH } \\
288169\end{array}$ & Cryptopipo \\
\hline 49 & Crypturellus & tataupa & Tinamidae & Tinamiformes & $\begin{array}{l}\text { UMMZ } \\
201948\end{array}$ & Crypturellus \\
\hline 50 & Cuculus & fugax & Cuculidae & Cuculiformes & $\begin{array}{l}\text { FMNH } \\
357420\end{array}$ & Cuculus \\
\hline 51 & Dendrocygna & bicolor & Anatidae & Anseriformes & $\begin{array}{l}\text { UMMZ } \\
219885\end{array}$ & Dendrocygna \\
\hline 52 & Deroptyus & accipitrinus & Psittacidae & Psittaciformes & $\begin{array}{l}\text { NHMUK } \\
\text { S/2002.14.2 }\end{array}$ & Deroptyus \\
\hline 53 & Diomedea & irrorata & Diomedeidae & Procellariiformes & $\begin{array}{l}\text { NHMUK } \\
\text { S/1963.28.4 }\end{array}$ & Phoebastria \\
\hline 54 & Elaenia & flavogaster & Tyrannidae & Passeriformes & $\begin{array}{l}\text { FMNH } \\
394495\end{array}$ & Elaenia \\
\hline 55 & Elanus & caerulenus & Accipitridae & Accipitriformes & $\begin{array}{l}\text { NHMUK } \\
1850.8 .15 .159\end{array}$ & 9 \\
\hline 56 & Eudromia & elegans & Tinamidae & Tinamiformes & $\begin{array}{l}\text { UMMZ } \\
156966\end{array}$ & Eudromia \\
\hline 57 & Eurypyga & helias & Eurypygidae & Eurypygiformes & $\begin{array}{l}\text { FMNH } \\
317341\end{array}$ & Eurypyga \\
\hline 58 & Falco & sparverius & Falconidae & Falconiformes & $\begin{array}{l}\text { UMMZ } \\
154462\end{array}$ & Falco \\
\hline 59 & Fregata & aquila & Fregatidae & Suliformes & $\begin{array}{l}\text { NHMUK } \\
1890.11 .3 .3\end{array}$ & Fregata \\
\hline 60 & Fringilla & coelebs & Fringillidae & Passeriformes & $\begin{array}{l}\text { OUMNH } \\
24647\end{array}$ & Fringilla \\
\hline 61 & Galbula & dea & Galbulidae & Piciformes & $\begin{array}{l}\text { FMNH } \\
376705\end{array}$ & Galbula \\
\hline 62 & Gavia & stellata & Gaviidae & Gaviiformes & $\begin{array}{l}\text { NHMUK } \\
\text { 1891.7.20.132 }\end{array}$ & $2^{\text {Gavia }}$ \\
\hline 63 & Glareola & pratincola & Glareolidae & Charadriiformes & $\begin{array}{l}\text { FMNH } \\
368875\end{array}$ & Glareola \\
\hline 64 & Grus & leucogeranus & Gruidae & Gruiformes & $\begin{array}{l}\text { UMZC } \\
344 . \mathrm{D}\end{array}$ & Grus \\
\hline 65 & Haematopus & ostralegus & Haematopodidae & Charadriiformes & $\begin{array}{l}\text { FMNH } \\
363899\end{array}$ & Haematopus \\
\hline 66 & Heliornis & senegalensis & Heliornithidae & Gruiformes & $\begin{array}{l}\text { UMZC } \\
209 . A\end{array}$ & Heliornis \\
\hline 67 & Hemiprocne & comata & Hemiprocnidae & Apodiformes & $\begin{array}{l}\text { UMMZ } \\
158224\end{array}$ & Hemiprocne \\
\hline 68 & Hirundinea & bellicosa & Tyrannidae & Passeriformes & $\begin{array}{l}\text { UMMZ } \\
200850\end{array}$ & Hirundinea \\
\hline $6 !$ & Hymenops & persipicillata & Tyrannidae & Passeriformes & $\begin{array}{l}\text { UMMZ } \\
158790\end{array}$ & Hymenops \\
\hline
\end{tabular}




\begin{tabular}{|c|c|c|c|c|c|c|}
\hline 70 & Indicator & exilis & Indicatoridae & Piciformes & $\begin{array}{l}\text { FMNH } \\
429726\end{array}$ & Indicator \\
\hline 71 & Ixobrychus & minutus & Ardeidae & Pelecaniformes & $\begin{array}{l}\text { NHMUK } \\
\text { S/2007.61.1 }\end{array}$ & Ixobrychus \\
\hline 72 & Jacana & jacana & Jacanidae & Charadriiformes & $\begin{array}{l}\text { NHMUK } \\
\text { S/1990.2.5 }\end{array}$ & Jacana \\
\hline 73 & Jynx & torquilla & Picidae & Piciformes & $\begin{array}{l}\text { NHMUK } \\
\text { S/1986.36.10 }\end{array}$ & Jynx \\
\hline 74 & Leptoptilos & crumeniferus & Ciconiidae & Ciconiiformes & $\begin{array}{l}\text { NHMUK } \\
\text { S/1952.3.182 }\end{array}$ & Leptoptilos \\
\hline 75 & Leptotila & rufaxilla & Columbidae & Columbiformes & $\begin{array}{l}\text { FMNH } \\
318659\end{array}$ & Leptotila \\
\hline 76 & Limosa & lapponica & Scolopacidae & Charadriiformes & $\begin{array}{l}\text { NHMUK } \\
\text { S/1994.46.20 }\end{array}$ & Limosa \\
\hline 77 & Malurus & melanocephalus & Maluridae & Passeriformes & $\begin{array}{l}\text { UMMZ } \\
224775\end{array}$ & Malurus \\
\hline 78 & Megalaima & chrysopogon & Megalaimidae & Piciformes & $\begin{array}{l}\text { NHMUK } \\
1850.8 .15 .28\end{array}$ & Megalaima \\
\hline 79 & Melanopareia & torquata & Melanopareiidae & Passeriformes & $\begin{array}{l}\text { FMNH } \\
335140\end{array}$ & Melanopareia \\
\hline 80 & Menura & novaehollandiae & Menuridae & Passeriformes & $\begin{array}{l}\text { FMNH } \\
336751\end{array}$ & Menura \\
\hline 81 & Micrastur & ruficollis & Falconidae & Falconiformes & $\begin{array}{l}\text { FMNH } \\
330226\end{array}$ & Micrastur \\
\hline 82 & Momotus & momota & Momotidae & Coraciiformes & $\begin{array}{l}\text { NHMUK } \\
\text { S/2015.23.4 }\end{array}$ & Momotus \\
\hline 83 & Monias & benschi & Mesitornithidae & Mesitornithiformes & $\begin{array}{l}\text { NHMUK } \\
1924.11 .29 .1\end{array}$ & Monias \\
\hline 84 & Myiobius & barbatus & Tyrannidae & Passeriformes & $\begin{array}{l}\text { FMNH } \\
386812\end{array}$ & Myiobius \\
\hline 85 & Myrmornis & torquata & Thamnophilidae & Passeriformes & $\begin{array}{l}\text { YPM } \\
106157\end{array}$ & Myrmornis \\
\hline 86 & Myrmothera & campanisona & Grallariidae & Passeriformes & $\begin{array}{l}\text { FMNH } \\
322348\end{array}$ & Myrmothera \\
\hline 87 & Neodrepanis & coruscans & Eurylaimidae & Passeriformes & $\begin{array}{l}\text { FMNH } \\
363807\end{array}$ & Neodrepanis \\
\hline 88 & Numida & meleagris & Numididae & Galliformes & $\begin{array}{l}\text { FMNH } \\
390428\end{array}$ & Numida \\
\hline 89 & Nyctibius & griseus & Nyctibiidae & Caprimulgiformes & $\begin{array}{l}\text { UMMZ } \\
136371\end{array}$ & Nyctibius \\
\hline 90 & Oceanodroma & leucorhoa & Hydrobatidae & Procellariiformes & $\begin{array}{l}\text { NHMUK } \\
\text { S/1953.3.10 }\end{array}$ & Oceanodroma \\
\hline 91 & Odontophorous & guttatus & Odontophoridae & Galliformes & $\begin{array}{l}\text { UMMZ } \\
210631\end{array}$ & Odontophorus \\
\hline 92 & Opisthocomus & hoazin & Opisthocomidae & Opisthocomiformes & $\begin{array}{l}\text { NHMUK } \\
\text { S/1961.6.1 }\end{array}$ & Opisthocomus \\
\hline 93 & Ortalis & ruficauda & Cracidae & Galliformes & $\begin{array}{l}\text { UMMZ } \\
155489\end{array}$ & Ortalis \\
\hline
\end{tabular}




\begin{tabular}{|c|c|c|c|c|c|}
\hline 94 Pandion & haliaetus & Pandionidae & Accipitriformes & $\begin{array}{l}\text { FMNH } \\
437336\end{array}$ & Pandion \\
\hline 95 Pedionomus & torquatus & Pedionomidae & Charadriiformes & $\begin{array}{l}\text { NHMUK } \\
\text { A / } 1970.12 .1\end{array}$ & Pedionomus \\
\hline 96 Pelagodroma & marina & Oceanitidae & Procellariiformes & $\begin{array}{l}\text { NHMUK } \\
\text { 1895.7.1.163 }\end{array}$ & Pelagodroma \\
\hline 97 Pelecanoides & urinatrix & Procellariidae & Procellariiformes & $\begin{array}{l}\text { NHMUK } \\
\text { S/2006.1.14 }\end{array}$ & Pelecanoides \\
\hline 98 Pelecanus & occidentalis & Pelecanidae & Pelecaniformes & $\begin{array}{l}\text { NHMUK } \\
\text { S/1973.66.16 }\end{array}$ & Pelecanus \\
\hline 99 Phaethon & lepturus & Phaethontidae & Phaethontiformes & $\begin{array}{l}\text { NHMUK } \\
1876.3 .16 .3\end{array}$ & Phaethon \\
\hline 100 Phalacrocorax & albiventer & Phalacrocoracida & ISuliformes & $\begin{array}{l}\text { NHMUK } \\
\text { S/2012.36.1 }\end{array}$ & Phalacrocorax \\
\hline 101 Phoenicopterus & roseus & Phoenicopteridae & Phoenicopteriforme & $\begin{array}{l}\text { sUMZC } \\
346 . \mathrm{B}\end{array}$ & Phoenicopterus \\
\hline 102 Phoeniculus & purpureus & Phoeniculidae & Bucerotiformes & $\begin{array}{l}\text { FMNH } \\
368956\end{array}$ & Phoeniculus \\
\hline 103 Picus & viridis & Picidae & Piciformes & $\begin{array}{l}\text { NHMUK } \\
\text { S/1982.5.1 }\end{array}$ & Picus \\
\hline 104 Piprites & chloris & Tyrannidae & Passeriformes & $\begin{array}{l}\text { FMNH } \\
290398\end{array}$ & Piprites \\
\hline 105 Poecile & atricapillus & Paridae & Passeriformes & $\begin{array}{l}\text { FMNH } \\
504323\end{array}$ & Poecile \\
\hline 106 Porphyrio & poliocephalus & Rallidae & Gruiformes & $\begin{array}{l}\text { NHMUK } \\
\text { S/1952.1.93 }\end{array}$ & Porphyrio \\
\hline 107 Probosciger & aterrimus & Cacatuidae & Psittaciformes & $\begin{array}{l}\text { NHMUK } \\
\text { S/2006.15.5 }\end{array}$ & Probosciger \\
\hline 108 Psittacus & erithacus & Psittacidae & Psittaciformes & $\begin{array}{l}\text { NHMUK } \\
\text { S/1992.41.60 }\end{array}$ & Psittacus \\
\hline 109 Psittrichas & fulgidus & Psittrichasiidae & Psittaciformes & $\begin{array}{l}\text { YPM } \\
141821\end{array}$ & Psittrichas \\
\hline 110 Psophia & crepitans & Psophiidae & Gruiformes & $\begin{array}{l}\text { FMNH } \\
105783\end{array}$ & Psophia \\
\hline 111 Pterocles & quadricinctus & Pteroclidae & Pterocliformes & $\begin{array}{l}\text { FMNH } \\
319937\end{array}$ & Pterocles \\
\hline 112 Ptilinopus & lechlancheri & Columbidae & Columbiformes & $\begin{array}{l}\text { FMNH } \\
358261\end{array}$ & Ptilinopus \\
\hline 113 Ptilonorhynchus & violaceus & Ptilonorhynchida & Aasseriformes & $\begin{array}{l}\text { UMMZ } \\
155483\end{array}$ & Ptilonorhynchus \\
\hline 114 Puffinus & tenuirostris & Procellariidae & Procellariiformes & $\begin{array}{l}\text { NHMUK } \\
1850.8 .15 .152\end{array}$ & ${ }_{2}^{\text {Puffinus }}$ \\
\hline 115 Pycnonotus & caffer & Pycnonotidae & Passeriformes & $\begin{array}{l}\text { NHMUK } \\
\text { S/1986.75.18 }\end{array}$ & Pycnonotus \\
\hline 116 Rallus & limnicola & Rallidae & Gruiformes & $\begin{array}{l}\text { FMNH } \\
501812\end{array}$ & Rallus \\
\hline 117 Ramphastos & ambiguus & Ramphastidae & Piciformes & $\begin{array}{l}\text { NHMUK } \\
\text { S/2002.21.2 }\end{array}$ & Ramphastos \\
\hline
\end{tabular}




\begin{tabular}{|c|c|c|c|c|c|}
\hline 118 Recurvirostra & avosetta & Recurvirostra & Charadriiformes & $\begin{array}{l}\text { NHMUK } \\
\text { S/1962.10.1 }\end{array}$ & Recurvirostra \\
\hline 119 Regulus & ignicapillus & Regulidae & Passeriformes & $\begin{array}{l}\text { NHMUK } \\
\text { S/1952.2.662 }\end{array}$ & Regulus \\
\hline 120 Rhynchocyclus & olivaceus & Tyrannidae & Passeriformes & $\begin{array}{l}\text { FMNH } \\
330600\end{array}$ & Rhynchocyclus \\
\hline 121 Rollandia & rolland & Podicipedidae & Podicipediformes & $\begin{array}{l}\text { UMMZ } \\
156975\end{array}$ & Rollandia \\
\hline 122 Rollulus & rouloul & Phasianidae & Galliformes & $\begin{array}{l}\text { NHMUK } \\
1891.7 .20 .87\end{array}$ & Rollulus \\
\hline 123 Rostratula & benghalensis & Rostratulidae & Charadriiformes & $\begin{array}{l}\text { FMNH } \\
319933\end{array}$ & Rostratula \\
\hline 124 Rupicola & peruvianus & Cotingidae & Passeriformes & $\begin{array}{l}\text { UMMZ } \\
119210\end{array}$ & Rupicola \\
\hline 125 Rynchops & niger & Laridae & Charadriiformes & $\begin{array}{l}\text { FMNH } \\
376309\end{array}$ & Rynchops \\
\hline 126 Sagittarius & serpentarius & Sagittariidae & Accipitriformes & $\begin{array}{l}\text { NHMUK } \\
\text { 1898.5.7.1 }\end{array}$ & Sagittarius \\
\hline 127 Sclerurus & mexicanus & Furnariidae & Passeriformes & $\begin{array}{l}\text { FMNH } \\
321715\end{array}$ & Sclerurus \\
\hline 128 Scopus & umbretta & Scopidae & Pelecaniformes & $\begin{array}{l}\text { FMNH } \\
313701\end{array}$ & Scopus \\
\hline 129 Spheniscus & humboldti & Spheniscidae & Sphenisciformes & $\begin{array}{l}\text { NHMUK } \\
\text { S/2000.7.1 }\end{array}$ & Spheniscus \\
\hline 130 Sterna & hirundo & Laridae & Charadriiformes & $\begin{array}{l}\text { NHMUK } \\
\text { S/1975.65.4 }\end{array}$ & Sterna \\
\hline 131 Streptoprocne & zonaris & Apodidae & Apodiformes & $\begin{array}{l}\text { FMNH } \\
85767\end{array}$ & Streptoprocne \\
\hline 132 Strix & aluco & Strigidae & Strigiformes & $\begin{array}{l}\text { NHMUK } \\
\text { S/2001.38.1 }\end{array}$ & Strix \\
\hline 133 Sula & dactylatra & Sulidae & Suliformes & $\begin{array}{l}\text { NHMUK } \\
1890.11 .3 .10\end{array}$ & Morus \\
\hline 134 Sylvia & borin & Sylviidae & Passeriformes & $\begin{array}{l}\text { FMNH } \\
385185\end{array}$ & Sylvia \\
\hline 135 Terenura & spodioptila & Thamnophilidae & Passeriformes & $\begin{array}{l}\text { FMNH } \\
344009\end{array}$ & Terenura \\
\hline 136 Tigrisoma & lineatum & Ardeidae & Pelecaniformes & $\begin{array}{l}\text { FMNH } \\
105528\end{array}$ & Tigrisoma \\
\hline 137 Tityra & semifasciata & Tityridae & Passeriformes & $\begin{array}{l}\text { NHMUK } \\
1891.7 .20 .15\end{array}$ & Tityra \\
\hline 138 Tockus & nasutus & Bucerotidae & Bucerotiformes & $\begin{array}{l}\text { NHMUK } \\
\text { S/1989.2.2 }\end{array}$ & Tockus \\
\hline 139 Todus & mexicanus & Todidae & Coraciiformes & $\begin{array}{l}\text { FMNH } \\
351174\end{array}$ & Todus \\
\hline 140 Торава & pyra & Trochilidae & Apodiformes & $\begin{array}{l}\text { FMNH } \\
318845\end{array}$ & Topaza \\
\hline 141 Treron & capellei & Columbidae & Columbiformes & $\begin{array}{l}\text { UMMZ } \\
220454\end{array}$ & Treron \\
\hline
\end{tabular}




\begin{tabular}{|c|c|c|c|c|c|}
\hline 142 Tringa & ochrophus & Scolopacidae & Charadriiformes & $\begin{array}{l}\text { FMNH } \\
368850\end{array}$ & Tringa \\
\hline 143 Trogon & melanurus & Trogonidae & Passeriformes & $\begin{array}{l}\text { FMNH } \\
290496\end{array}$ & Trogon \\
\hline 144 Turdus & olivater & Turdidae & Passeriformes & $\begin{array}{l}\text { FMNH } \\
319675\end{array}$ & Turdus \\
\hline 145 Turnix & varius & Turnicidae & Charadriiformes & $\begin{array}{l}\text { NHMUK } \\
\text { S/1952.2.142 }\end{array}$ & Turnix \\
\hline 146 Tyrannus & tyrannus & Tyrannidae & Passeriformes & $\begin{array}{l}\text { FMNH } \\
487521\end{array}$ & Tyrannus \\
\hline 147 Tyto & alba & Tytonidae & Strigiformes & $\begin{array}{l}\text { NHMUK } \\
\text { S/1989.22.1 }\end{array}$ & Tyto \\
\hline 148 Uрира & epops & Upupidae & Bucerotiformes & $\begin{array}{l}\text { FMNH } \\
352821\end{array}$ & Upupa \\
\hline 149 Vultur & gryphus & Cathartidae & Accipitriformes & $\begin{array}{l}\text { NHMUK } \\
\text { S/1955.5.11 }\end{array}$ & Vultur \\
\hline
\end{tabular}




\section{Redundancy analysis}

\begin{tabular}{|c|c|c|c|c|}
\hline Ecological category & Food & Flight & Foot-use & Total \\
\hline $\begin{array}{l}\text { Term-wise } \\
\text { (all birds) }\end{array}$ & $\begin{array}{l}\mathrm{e}=0.13 \\
p=0.052\end{array}$ & $\begin{array}{l}\mathrm{e}=0.14 ; \\
p=0.026\end{array}$ & $\begin{array}{l}\mathrm{e}=0.13 ; \\
p=0.038\end{array}$ & $\mathrm{Na}$ \\
\hline $\begin{array}{l}\text { Marginal } \\
\text { (all birds) }\end{array}$ & $\begin{array}{l}\mathrm{e}=0.15 \\
p=0.015\end{array}$ & $\begin{array}{l}\mathrm{e}=0.14 \\
p=0.034\end{array}$ & $\begin{array}{l}\mathrm{e}=0.13 \\
p=0.030\end{array}$ & $\mathrm{Na}$ \\
\hline $\begin{array}{l}\text { Pure } \\
\text { (all birds) }\end{array}$ & $\begin{array}{l}\mathrm{e}=0.13 \\
p=0.13\end{array}$ & $\begin{array}{l}\mathrm{e}=0.13 \\
p=0.11\end{array}$ & $\begin{array}{l}\mathrm{e}=0.12 \\
p=0.15\end{array}$ & $\mathrm{Na}$ \\
\hline $\begin{array}{l}\text { Total } \\
\text { (all birds) }\end{array}$ & $\mathrm{Na}$ & $\mathrm{Na}$ & $\mathrm{Na}$ & $\begin{array}{l}\mathrm{e}=0.40 \\
p=0.005\end{array}$ \\
\hline $\begin{array}{l}\text { Term-wise } \\
\text { (Telluraves) }\end{array}$ & $\begin{array}{l}\mathrm{e}=0.083 \\
p=0.46\end{array}$ & $\begin{array}{l}\mathrm{e}=0.077 \\
p=0.52\end{array}$ & $\begin{array}{l}\mathrm{e}=0.092 \\
p=0.35\end{array}$ & $\mathrm{Na}$ \\
\hline $\begin{array}{l}\text { Marginal } \\
\text { (Telluraves) }\end{array}$ & $\begin{array}{l}\mathrm{e}=0.097 \\
p=0.34\end{array}$ & $\begin{array}{l}\mathrm{e}=0.053 \\
p=0.85\end{array}$ & $\begin{array}{l}\mathrm{e}=0.093 \\
p=0.38\end{array}$ & $\mathrm{Na}$ \\
\hline $\begin{array}{l}\text { Pure } \\
\text { (Telluraves) }\end{array}$ & $\begin{array}{l}\mathrm{e}=0.083 \\
p=0.46\end{array}$ & $\begin{array}{l}\mathrm{e}=0.064 ; \\
p=0.73\end{array}$ & $\begin{array}{l}\mathrm{e}=0.12 \\
p=0.16\end{array}$ & $\mathrm{Na}$ \\
\hline $\begin{array}{l}\text { Total } \\
\text { (Telluraves) }\end{array}$ & $\mathrm{Na}$ & $\mathrm{Na}$ & $\mathrm{Na}$ & $\begin{array}{l}\mathrm{e}=0.25 \\
p=0.46\end{array}$ \\
\hline $\begin{array}{l}\text { Term-wise } \\
\text { (non-Telluraves) }\end{array}$ & $\begin{array}{l}\mathrm{e}=0.18 \\
p=0.029\end{array}$ & $\begin{array}{l}\mathrm{e}=0.037 \\
p=0.85\end{array}$ & $\begin{array}{l}\mathrm{e}=0.12 \\
p=0.17\end{array}$ & $\mathrm{Na}$ \\
\hline $\begin{array}{l}\text { Marginal } \\
\text { (non-Telluraves) }\end{array}$ & $\begin{array}{l}\mathrm{e}=0.13 \\
p=0.14\end{array}$ & $\begin{array}{l}\mathrm{e}=0.038 \\
p=0.86\end{array}$ & $\begin{array}{l}\mathrm{e}=0.12 \\
p=0.16\end{array}$ & $\mathrm{Na}$ \\
\hline $\begin{array}{l}\text { Pure } \\
\text { (non-Telluraves) }\end{array}$ & $\begin{array}{l}\mathrm{e}=0.18 \\
p=0.033\end{array}$ & $\begin{array}{l}\mathrm{e}=0.097 \\
p=0.30\end{array}$ & $\begin{array}{l}\mathrm{e}=0.14 \\
p=0.094\end{array}$ & $\mathrm{Na}$ \\
\hline $\begin{array}{l}\text { Total } \\
\text { (non-Telluraves) }\end{array}$ & $\mathrm{Na}$ & $\mathrm{Na}$ & $\mathrm{Na}$ & $\begin{array}{l}\mathrm{e}=0.33 \\
p=0.096\end{array}$ \\
\hline
\end{tabular}

Supplementary Table 2: Proportion of variance (above) and $p$-values (below) of ecological constraints that structure the difference between size and shape-integration, derived from distance-based redundancy analysis. Sample size $=149$ birds, permutations $=100,000$. Significant relationships $(p<0.05$, determined by permutation) are presented in bold. 'Total' analyses explore the proportion of variance explained in an analysis considering all ecological categories simultaneously. 'Term-wise' effects explore ecological contributions sequentially. 'Marginal' tests significance of individual ecological categories in a multivariate context. 'Pure' effects for each ecological category are determined by treating all other categories as conditional variables. 


\section{References}

[1] J. del Hoyo, A. Elliott, J. Sargatal, D. Christie, and G. Krwan, "Handbook of the birds of the world alive.," 2020.

[2] R. Wanless, "Aerial attitude," Africa: Birds and Birding, vol. 7, pp. 46-41, 2002.

[3] D. Gressler and M. Â. Marini, "Nest, eggs and nestling of the collared crescentchest melanopareia torquata in the cerrado region, brazil," Revista Brasileira de Ornitologia, vol. 15, pp. 574-576, 2007.

[4] B. R. Barber and M. B. Robbins, "Nest and eggs of the tepui antpitta (myrmothera simplex)," The Wilson Journal of Ornithology, vol. 114, no. 3, pp. 287-288, 2002.

[5] L. Walkinshaw, "Observations on limpkin nesting.," Quarterly publication of the Florida ornithological society, vol. 10, no. 3, pp. 45-64, 1982.

[6] S. M. Gatesy and K. M. Middleton, "Bipedalism, flight, and the evolution of theropod locomotor diversity," Journal of Vertebrate Paleontology, vol. 17, no. 2, pp. 308-329, 1997.

[7] M. Bennett, "Allometry of the leg muscles of birds," Journal of Zoology, vol. 238, no. 3, pp. 435443, 1996.

[8] T. D. Jones, J. O. Farlow, J. A. Ruben, D. M. Henderson, and W. J. Hillenius, "Cursoriality in bipedal archosaurs," Nature, vol. 406, no. 6797, pp. 716-718, 2000.

[9] A. N. Silva, R. Nunes, D. C. Estrela, G. Malafaia, and A. Castro, "Behavioral repertoire of the poorly known red-legged seriema, cariama cristata (cariamiformes: Cariamidae)," Rev. Bras. Ornitol, vol. 24, pp. 73-79, 2016.

[10] G. Maloiy, R. M. Alexander, R. Njau, and A. Jayes, "Allometry of the legs of running birds," Journal of Zoology, vol. 187, no. 2, pp. 161-167, 1979.

[11] G. Hayes and R. M. Alexander, "The hopping gaits of crows (corvidae) and other bipeds," Journal of Zoology, vol. 200, no. 2, pp. 205-213, 1983.

[12] R. O. Prum, J. S. Berv, A. Dornburg, D. J. Field, J. P. Townsend, E. M. Lemmon, and A. R. Lemmon, "A comprehensive phylogeny of birds (aves) using targeted next-generation dna sequencing," Nature, vol. 526, no. 7574, pp. 569-573, 2015.

[13] R. Raikow, A. King, and J. McLelland, "Form and function in birds," 1985.

[14] K. M. Middleton, "The morphological basis of hallucal orientation in extant birds," Journal of morphology, vol. 250, no. 1, pp. 51-60, 2001.

[15] W. J. Bock and W. D. Miller, "The scansorial foot of the woodpeckers, with comments on the evolution of perching and climbing feet in birds. american museum novitates; no. 1931," American Museum of Natural History, digital library, 1959.

[16] D. Sustaita, E. Pouydebat, A. Manzano, V. Abdala, F. Hertel, and A. Herrel, "Getting a grip on tetrapod grasping: form, function, and evolution," Biological Reviews, vol. 88, no. 2, pp. 380-405, 2013. 
[17] G. Mayr, "On the osteology and phylogenetic affinities of the pseudasturidae-lower eocene stemgroup representatives of parrots (aves, psittaciformes)," Zoological Journal of the Linnean Society, vol. 136, no. 4, pp. 715-729, 2002.

[18] J. J. Negro, C. Pertoldi, E. Randi, J. J. Ferrero, J. M. López-Caballero, D. Rivera, and E. Korpimäki, "Convergent evolution of elanus kites and the owls," Journal of Raptor Research, vol. 40, no. 3, pp. 222-225, 2006.

[19] A. E. de los Monteros, "Higher-level phylogeny of trogoniformes," Molecular Phylogenetics and Evolution, vol. 14, no. 1, pp. 20-34, 2000.

[20] M. A. Madan, E. J. Rayfield, and J. A. Bright, "Scaling and functional morphology in strigiform hind limbs," Scientific reports, vol. 7, p. 44920, 2017.

[21] T. H. Quinn and J. J. Baumel, "The digital tendon locking mechanism of the avian foot (aves)," Zoomorphology, vol. 109, no. 5, pp. 281-293, 1990.

[22] L. Einoder and A. Richardson, "The digital tendon locking mechanism of owls: variation in the structure and arrangement of the mechanism and functional implications," Emu-Austral Ornithology, vol. 107, no. 3, pp. 223-230, 2007.

[23] D. T. Ksepka and J. A. Clarke, "A new stem parrot from the green river formation and the complex evolution of the grasping foot in pan-psittaciformes," Journal of Vertebrate Paleontology, vol. 32, no. 2, pp. 395-406, 2012.

[24] J. Carril, M. C. Mosto, M. B. Picasso, and C. P. Tambussi, "Hindlimb myology of the monk parakeet (aves, psittaciformes)," Journal of morphology, vol. 275, no. 7, pp. 732-744, 2014.

[25] A. Zeffer and U. L. Norberg, "Leg morphology and locomotion in birds: requirements for force and speed during ankle flexion," Journal of Experimental Biology, vol. 206, no. 6, pp. 1085-1097, 2003.

[26] U. M. Norberg, "Morphology of the wings, legs and tail of three coniferous forest tits, the goldcrest, and the treecreeper in relation to locomotor pattern and feeding station selection," Philosophical Transactions of the Royal Society of London. B, Biological Sciences, vol. 287, no. 1019, pp. 131-165, 1979.

[27] A. B. Ward, P. D. Weigl, and R. M. Conroy, "Functional morphology of raptor hindlimbs: implications for resource partitioning," The Auk, vol. 119, no. 4, pp. 1052-1063, 2002.

[28] S. Billerman, B. Keeney, P. Rodewald, and T. Schulenberg, "Birds of the world."

[29] C. H. Fry and K. Fry, Kingfishers, bee-eaters and rollers. A\&C Black, 2010.

[30] L. C. Johansson and R. A. Norberg, "Delta-wing function of webbed feet gives hydrodynamic lift for swimming propulsion in birds," Nature, vol. 424, no. 6944, pp. 65-68, 2003.

[31] W. DeW, "Notes on the structure of anseranas semipalmata," The Auk, pp. 562-564, 1919.

[32] G. T. Clifton and A. A. Biewener, "Foot-propelled swimming kinematics and turning strategies in common loons," Journal of Experimental Biology, vol. 221, no. 19, p. jeb168831, 2018. 
[33] R. W. Schreiber, G. E. Woolfenden, and W. E. Curtsinger, "Prey capture by the brown pelican," The Auk, pp. 649-654, 1975.

[34] A. M. Heers and K. P. Dial, "Wings versus legs in the avian bauplan: development and evolution of alternative locomotor strategies," Evolution, vol. 69, no. 2, pp. 305-320, 2015. 